\title{
Influence of aggregate fracture on shear transfer through cracks in reinforced concrete
}

\author{
J. Sagaseta \\ École Polytechnique Fédérale de Lausanne (EPFL), Lausanne, Switzerland
}

\section{R. L. Vollum}

Department of Civil \& Environmental Engineering, Imperial College London, London, UK

Design methods for shear in reinforced concrete structures typically rely upon shear transfer through cracks, which depends upon the crack opening and sliding displacements and the roughness of the crack surfaces. The effectiveness of shear transfer through aggregate interlock is commonly believed to be reduced if the coarse aggregate fractures at cracks, as is frequently the case in high-strength and lightweight aggregate concretes. This paper describes two sets of push-off tests that were carried out to investigate the effect of aggregate fracture on shear transfer through cracks. Marine dredged gravel was used in one set of specimens and limestone in the other. The cracks typically passed around the gravel aggregate but through the limestone aggregate. The experimental results are compared with the predictions of various existing analytical models including those in design codes MC90, Eurocode 2 and ACl-318. The paper also examines the contribution of aggregate interlock to the shear strength of a parallel set of reinforced concrete beams, tested by the authors, which used the same types of aggregate as the push-off specimens.

\section{Notation}

$A_{\text {sw }} \quad$ area of both legs of each stirrup

a maximum aggregate size

$b_{\text {cr }} \quad$ width of shear plane in push-off specimen

$b_{\mathrm{w}} \quad$ width of beam web

$b_{1} \quad$ total width of push-off specimen

$b_{2} \quad$ total depth of push-off specimen

C cohesion

$d \quad$ effective depth

$E_{\mathrm{g}}, k \quad$ shear stiffness $(\tau / s)$

$f_{\mathrm{c}}{ }^{\prime} \quad$ concrete cylinder strength

$f_{\text {ci }} \quad$ crack normal stresses (modified compression field theory (MCFT) notation)

$f_{\mathrm{ct}} \quad$ concrete tensile strength

$f_{\text {cu }} \quad$ concrete cube strength

$f_{\mathrm{y}} \quad$ yield strength of shear reinforcement

$H_{\mathrm{cr}} \quad$ height of shear plane in push-off specimen

$n$ number of stirrups in push-off specimen

$r \quad$ crack displacement ratio $(s / w)$

$V \quad$ shear force

$V_{\text {test }} \quad$ measured shear strength

$v_{\text {cimax }} \quad$ maximum shear resistance at crack (MCFT notation)

$v_{\text {eff }} \quad$ effective shear stress on crack

$w_{0}$

initial crack width

$\begin{array}{ll}w, s & \begin{array}{l}\text { crack opening (width) and sliding (slip) } \\ \text { displacements }\end{array} \\ w_{\text {peak }}, s_{\text {peak }} & \begin{array}{l}\text { crack opening and sliding displacements at peak } \\ \text { load } \\ \mu\end{array} \\ \rho_{\mathrm{v}} & \text { coefficient of friction along crack plane } \\ \sigma_{\mathrm{ncr}} & \text { normal stress to crack plane } \\ \tau & \text { shear stress } \\ \tau_{\mathrm{cr}} & \text { shear stress along crack plane } \\ \tau_{\mathrm{ult}} & \text { maximum shear stress along crack plane }\end{array}$

\section{Introduction}

The mechanics of shear transfer through aggregate interlock is complex because several mechanisms are involved in which normal and shear stresses interact. Cracks tend to 'dilate' as they slide due to aggregate particles sliding over each other. Normal stresses are introduced at the crack face if the crack widening is constrained by reinforcement or otherwise. Furthermore, the shear stiffness decreases as cracks widen due to contact being lost between the crack faces. Modelling aggregate interlock is complex owing to difficulties in defining crack roughness and assessing the effect of localised stresses around embedded bars, tension stiffening, normal stresses, dowel action and time-dependent effects such as creep. Pre-cracked push-off specimens like 


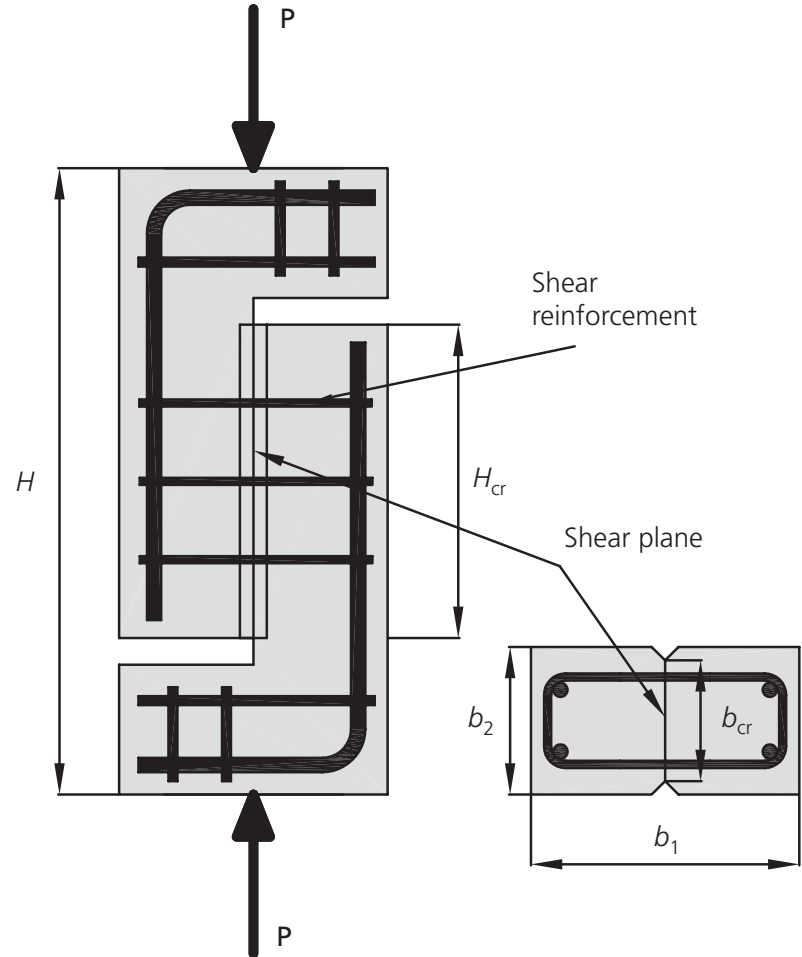

(a)

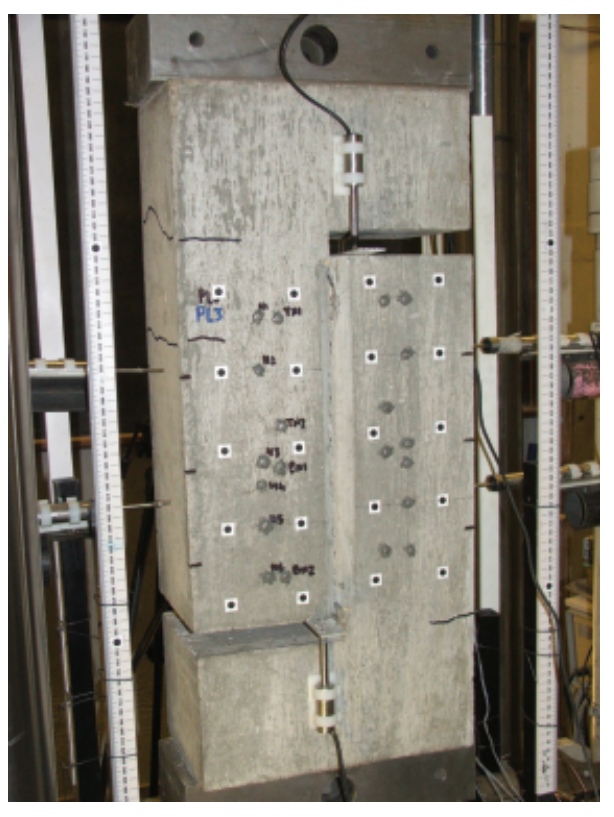

(b)

Figure 1. Push-off test arrangement: (a) geometry definition and

(b) testing rig and instrumentation

that shown in Figure 1 have been used to study shear transfer through aggregate interlock by Mattock et al. (1975), Walraven and Reinhardt (1981) and Hamadi (1976), among others.

\section{Push-off tests}

Test specimens

Six push-off tests were conducted to investigate the influence of aggregate fracture on shear transfer through cracks. The geometry of the specimens is given in Figure 1 and Table 1. Figure 2 shows details of the tested specimens, which were labelled according to the number of stirrups crossing the crack plane. The crack surface area $\left(H_{\mathrm{cr}} \times b_{\mathrm{cr}}\right.$, see Figure 1) was similar to that in beams tested by the authors (Sagaseta, 2008; Sagaseta and Vollum, 2010; 2011) to facilitate the assessment of aggregate interlock in beams. The specimens were cast in two groups. The coarse aggregate (maximum size $10 \mathrm{~mm}$ ) was limestone in the first group (PL2, PL2b, PL3 and PL4) and marine dredged gravel aggregate in the second group (PG2 and PG3). Table 2 gives details of the concrete properties. The limestone aggregate was crushed from a calcareous rock whereas the marine gravel was siliceous and more spherical in shape. The cracks passed through the limestone aggregate but around the gravel aggregate. The explanation for the fracture of the limestone appears to lie in the observation that

\begin{tabular}{lcccc}
\hline $\begin{array}{l}\text { Dimension: } \\
\mathrm{mm}\end{array}$ & $\begin{array}{c}\text { Mattock et al. } \\
(1975)\end{array}$ & $\begin{array}{c}\text { Hamadi } \\
(1976)\end{array}$ & $\begin{array}{c}\text { Walraven and } \\
\text { Reinhardt } \\
(1981)\end{array}$ & This work \\
\hline$H$ & $660 \cdot 4$ & 700 & 600 & 700 \\
$H_{\mathrm{cr}}$ & $304 \cdot 8$ & 350 & 300 & 350 \\
$b_{1}$ & $355 \cdot 6$ & 300 & 400 & 300 \\
$b_{2}$ & $177 \cdot 8$ & 150 & 120 & 165 \\
$b_{\mathrm{cr}}$ & $177 \cdot 8$ & 120 & 120 & 135
\end{tabular}

Table 1. Dimensions of push-off specimens (refer to Figure 1 for notation) 


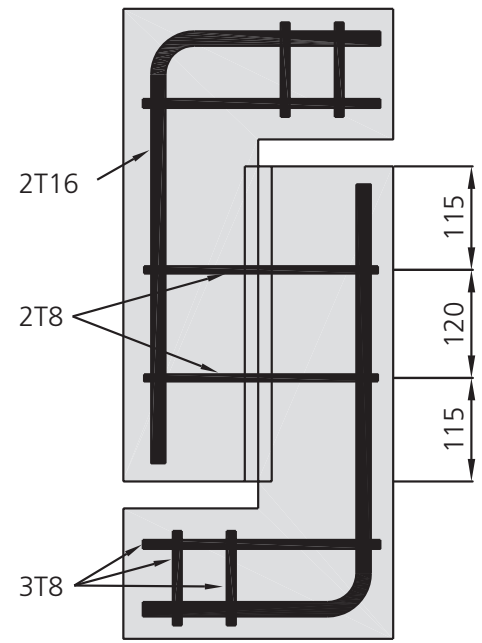

PG2, PL2 $\left(\rho_{v}=0.42 \%\right)$

(a)

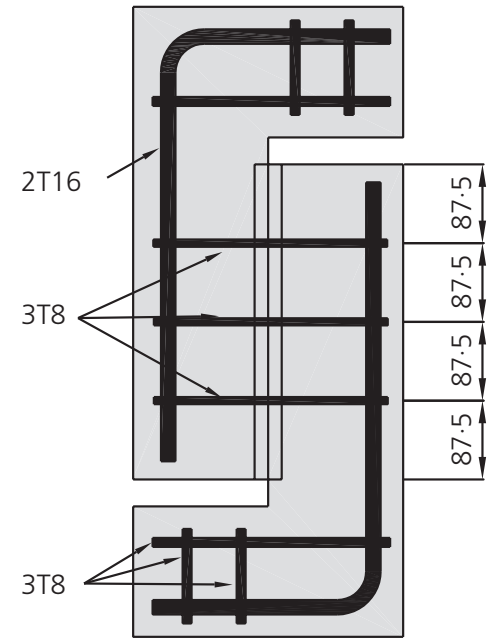

PG3, PL3 $\left(\rho_{v}=0.64 \%\right)$

(b)

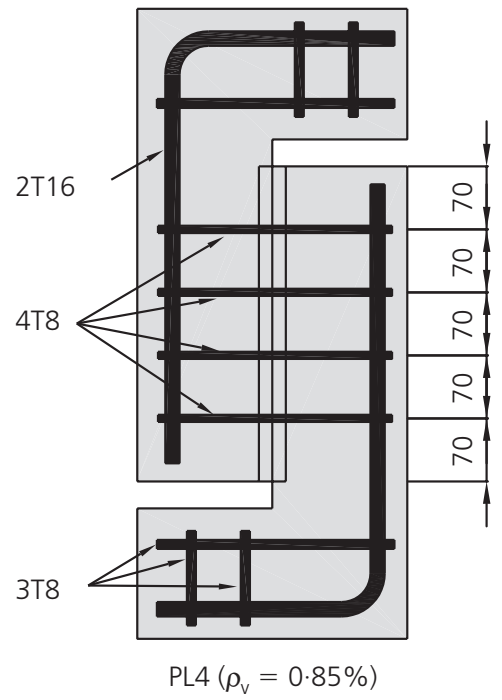

(c)

Figure 2. Reinforcement layout in push-off specimens: (a) PG2,

PL2; (b) PG3, PL3; (c) PL4. Concrete cylinder strength

$f_{c}^{\prime}=31.7 \mathrm{MPa}$ (for PG specimens) and 53.11 MPa (for PL).

Reinforcement steel $f_{y}=550 \mathrm{MPa}$ (T8) and $600 \mathrm{MPa}$ (T16).

Dimensions in $\mathrm{mm}$

\begin{tabular}{lcc}
\hline $\begin{array}{l}\text { Concrete } \\
\text { properties }\end{array}$ & $\begin{array}{c}\mathrm{PL}^{*} \\
\text { (limestone) }\end{array}$ & $\begin{array}{c}\mathrm{PG} \\
\text { (gravel) }\end{array}$ \\
\hline$f_{\mathrm{c}}^{\prime}: \mathrm{MPa}$ & $53 \cdot 1$ & 31.7 \\
$f_{\mathrm{cu}}: \mathrm{MPa}$ & 60.3 & $39.6 \dagger$ \\
$f_{\mathrm{t}}: \mathrm{MPa}$ (Brazilian) & 3.79 & 2.80 \\
\hline
\end{tabular}

* Beams BL and BG (Sagaseta, 2008) were cast using the same concrete as specimens PL and PG respectively

+ Cube tests not available for PG; value taken as $1.25 f_{c}$

Table 2. Concrete properties in push-off tests

limestone aggregates can bond strongly with cement paste due to a chemical reaction between the calcite in the aggregate and calcium hydroxide in the hydrated cement (Monteiro and Mehta, 1986).

\section{Instrumentation}

Loads and platen-to-platen displacements were measured directly within the loading rig. The deformation of the specimen was measured with six displacement transducers (linear variable differential transformers (LVDTs)) positioned as shown in Figure 3. Displacements were also measured using digital photogrammetric surveying; this is a relatively new technique based on image processing. The photogrammetric targets were placed on a $75 \mathrm{~mm} \times 75 \mathrm{~mm}$ grid as shown in Figures 1(b) and 3. Digital pictures were taken at each load step from both sides of the specimen. The working distance between the camera and the face

of the test specimens was around $500 \mathrm{~mm}$. Crack opening and sliding displacements were calculated at four different positions along the crack with computer software developed by McCarthy (2007) at Imperial College London. The photogrammetric results were comparable with the LVDT readings (Sagaseta, 2008). The maximum errors in the photogrammetric measurements were around $0.03 \mathrm{~mm}$ relative to a stationary reference; this is possibly acceptable for displacements, but not strains in uncracked concrete.

Relative crack opening $(w)$ and sliding $(s)$ displacements were derived at various points along the crack plane from displacements measured between crosses of Demec discs, LVDTs and photogrammetric targets. The gauge length was $150 \mathrm{~mm}$ between the Demec discs and the LVDTs and $75 \mathrm{~mm}$ between the photogrammetric targets. The crack opening and sliding displacements were calculated at each cross using the procedure illustrated in Figure 4, which was used by Hamadi (1976) and Hamadi and Regan (1980), among others. The initial crack displacements $\left(w_{0}, s_{0}\right)$ could only be calculated from the Demec readings since the LVDTs and photogrammetric targets were installed after pre-cracking.

Strains were measured in the stirrups with pairs of surfacemounted strain gauges positioned opposite each other. Strains were measured in both legs of the stirrups in specimen PL2 but in only one leg of the other specimens. Two additional strain gauges were attached to the top and bottom stirrups, $100 \mathrm{~mm}$ from the crack in specimens P2 and P3 to determine the strain distribution along the stirrups. Strains were also measured in the 


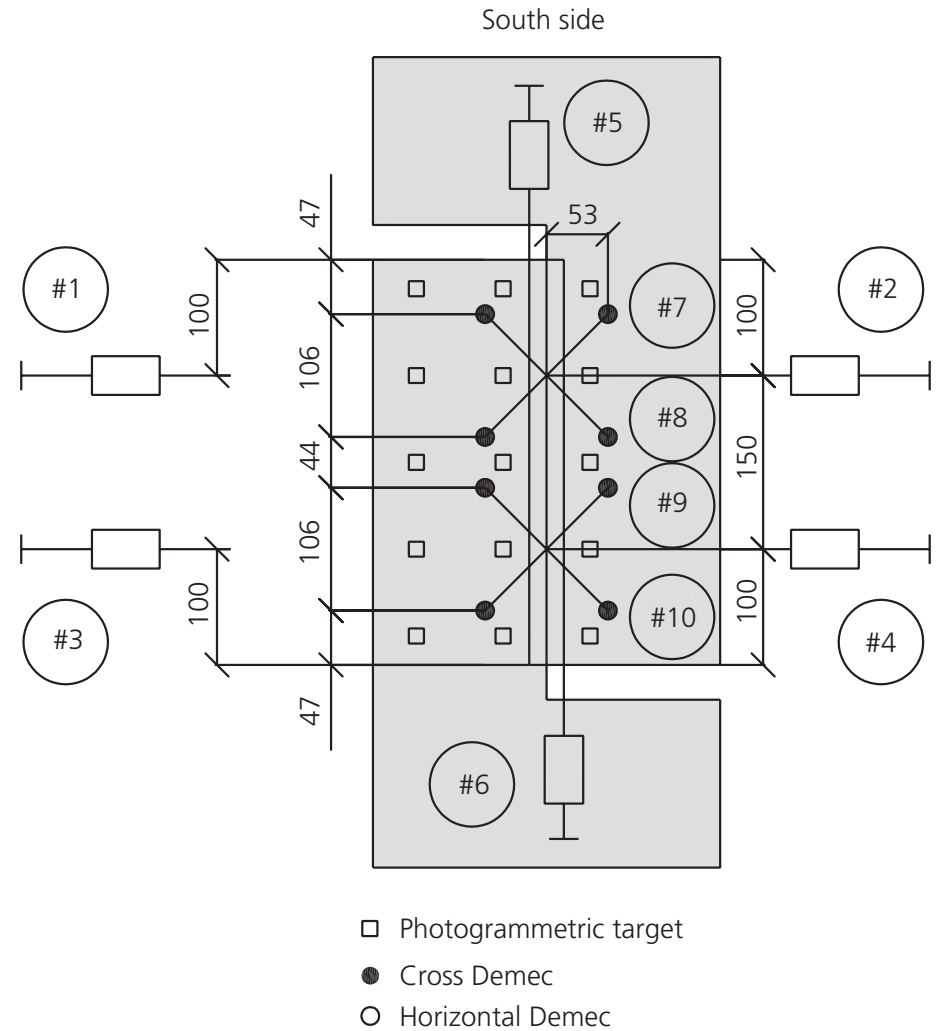

(a)

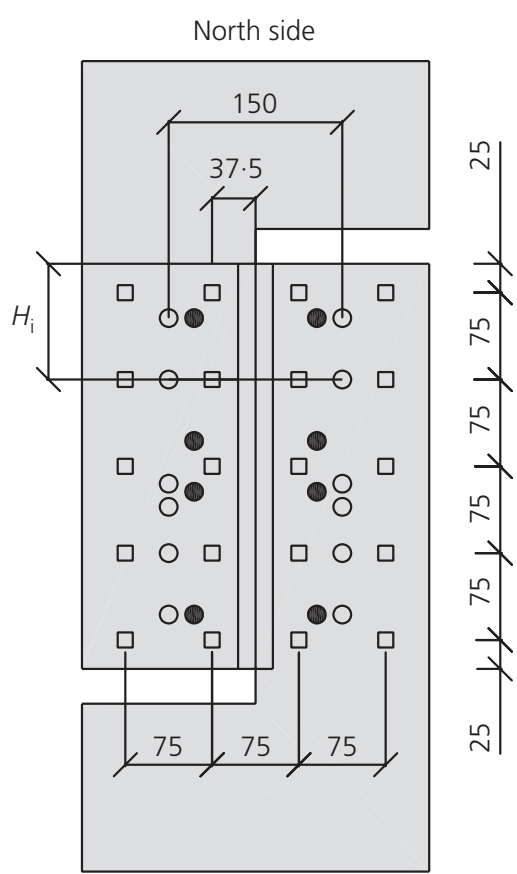

(b)

Figure 3. Instrumentation used in push-off tests: (a) LVDTs;

(b) Demec and photogrammetric targets. Dimensions in $\mathrm{mm}$

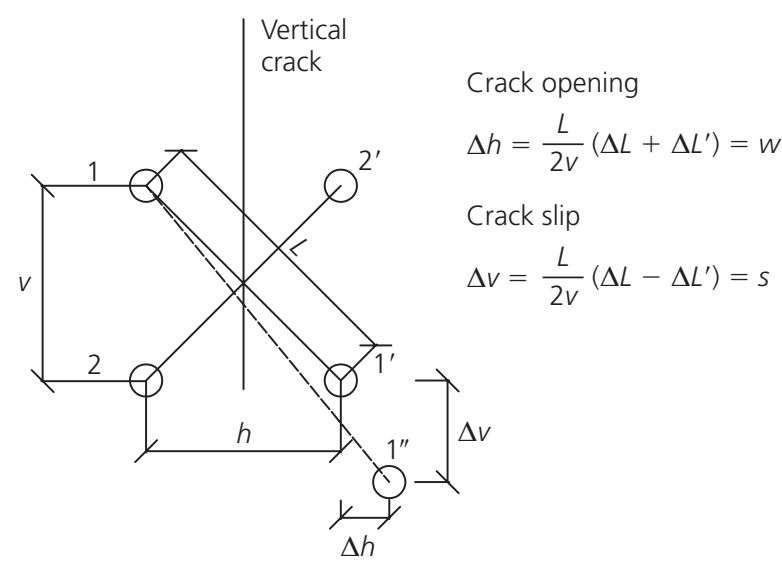

Figure 4. Procedure used to obtain relative crack displacements $\left(\Delta L: 1-1^{\prime} ; \Delta L^{\prime}: 2-2^{\prime}\right)$ (adapted from Hamadi, 1976)

concrete surface over the stirrups between Demec points placed at $150 \mathrm{~mm}$ centres.

The specimens were pre-cracked with a laterally loaded wedge that was forced into the V-shaped groove visible in Figure 1. The resulting initial crack widths $w_{0}$ varied between $0 \cdot 1$ and $0 \cdot 3 \mathrm{~mm}$
(Table 3) with small variations along the crack plane. The largest deviations in $w_{0}$ occurred in the specimens with the least number of stirrups. The variations in crack width occurred mainly between opposite faces of the specimens and not along the crack plane. The slight asymmetry in the crack plane decreased as the specimens were loaded vertically with the crack widths on each side becoming similar soon after loading.

The specimens were loaded vertically from the top through a loading plate attached to a spherical seating. Mini-rollers were used to release lateral displacements at the base of the specimens. The test was carried out in displacement control with a loading rate of $0.1 \mathrm{~mm} / \mathrm{min}$. Demec readings were taken at displacement increments of $0.1 \mathrm{~mm}$ in the first cycle and $0.2 \mathrm{~mm}$ in the second and third cycles. The specimens were initially loaded to peak load, which was reached without significant damage to the specimens. The specimens were then unloaded and reloaded twice more. The additional load cycles provide useful information on the influence of crack width on the shear stiffness on reloading.

\section{Experimental results}

Table 3 gives the crack opening and sliding displacements at peak load $\left(w_{\text {peak }}, s_{\text {peak }}\right)$ for each load cycle. The initial crack width $w_{0}$ was calculated by averaging the readings from the four Demec 


\begin{tabular}{|c|c|c|c|c|c|c|}
\hline Specimen & Cycle & $\begin{array}{l}w_{0}: \\
m m\end{array}$ & $\begin{array}{l}\mathrm{SD} * \\
\mathrm{~mm}\end{array}$ & $\begin{array}{c}\tau_{\text {peak }} \\
\mathrm{MPa}\end{array}$ & $\begin{array}{c}W_{\text {peak }}: \\
\mathrm{mm}\end{array}$ & $\begin{array}{l}S_{\text {peak }}: \\
\mathrm{mm}\end{array}$ \\
\hline PL2 & 1 & $0 \cdot 132$ & 0.051 & $4 \cdot 85$ & 0.36 & 0.29 \\
\hline \multirow[t]{2}{*}{$\left(\rho_{\mathrm{v}}=0.42 \%\right)$} & 2 & 0.296 & 0.043 & $4 \cdot 52$ & 0.48 & 0.57 \\
\hline & 3 & 0.705 & 0.091 & $3 \cdot 85$ & 0.93 & 1.61 \\
\hline PL2b) & 1 & 0.093 & 0.068 & $5 \cdot 82$ & 0.24 & 0.20 \\
\hline \multirow[t]{3}{*}{$\left(\rho_{\mathrm{v}}=0.42 \%\right)$} & 2 & 0.491 & 0.098 & $4 \cdot 76$ & 0.57 & 0.67 \\
\hline & 3 & 0.711 & $0 \cdot 146$ & $4 \cdot 48$ & 0.75 & 0.98 \\
\hline & 4 & 0.804 & $0 \cdot 169$ & $4 \cdot 40$ & 0.85 & $1 \cdot 15$ \\
\hline PL3 & 1 & $0 \cdot 123$ & 0.043 & $5 \cdot 55$ & 0.37 & 0.40 \\
\hline \multirow{2}{*}{$\left(\rho_{\mathrm{v}}=0.64 \%\right)$} & 2 & $0 \cdot 380$ & 0.044 & $5 \cdot 17$ & 0.47 & 0.71 \\
\hline & 3 & 0.545 & 0.066 & $4 \cdot 76$ & 0.61 & $1 \cdot 16$ \\
\hline PL4 & 1 & $0 \cdot 120$ & 0.024 & $7 \cdot 10$ & 0.38 & 0.50 \\
\hline \multirow{2}{*}{$\left(\rho_{\mathrm{v}}=0.85 \%\right)$} & 2 & 0.418 & 0.021 & $6 \cdot 63$ & 0.52 & 0.89 \\
\hline & 3 & 0.766 & 0.090 & $6 \cdot 03$ & 0.85 & 1.77 \\
\hline PG2 & 1 & 0.273 & $0 \cdot 148$ & $3 \cdot 67$ & 0.65 & 0.93 \\
\hline \multirow{2}{*}{$\left(\rho_{\mathrm{v}}=0.42 \%\right)$} & 2 & 0.714 & $0 \cdot 108$ & $3 \cdot 46$ & 0.79 & 1.46 \\
\hline & 3 & 0.877 & 0.043 & $3 \cdot 31$ & 0.92 & $2 \cdot 02$ \\
\hline PG3 & 1 & 0.081 & 0.039 & 4.91 & 0.51 & 0.60 \\
\hline \multirow[t]{2}{*}{$\left(\rho_{\mathrm{v}}=0.64 \%\right)$} & 2 & $0 \cdot 395$ & 0.082 & $4 \cdot 72$ & 0.68 & 1.00 \\
\hline & 3 & 0.628 & 0.080 & 4.45 & 0.92 & 1.64 \\
\hline
\end{tabular}

* Standard deviation of four readings of $w_{0}$ at both sides of the crack

Table 3. Summary of push-off test results

crosses on each specimen. Table 3 shows that the relative crack displacements at maximum shear stress were greater in the gravel (PG) than in the limestone (PL) specimens. Figures 5(a) and 5(b) show that the crack paths $(w-s)$ were very similar in the gravel and limestone specimens. The mean ratio between incremental opening and sliding displacements $\left(\left(w-w_{0}\right) / s\right)$ is a measure of crack dilatancy. The ratio $\left(w-w_{0}\right) / s$ (Figures $5(\mathrm{a})$ and (b)) was around 0.5 in the first two load cycles of the PG and PL tests, which is similar to that measured by Walraven and Reinhardt (1981) in their push-off tests on lightweight concrete specimens with embedded stirrups and externally restrained specimens with $16 \mathrm{~mm}$ gravel aggregate. The ratio $\left(w-w_{0}\right) / s$ was closer to 1.0 in Walraven and Reinhardt's (1981) tests with embedded stirrups and $16 \mathrm{~mm}$ gravel aggregate, which suggests that the crack roughness was greater than in the current tests.

Millard and Johnson (1985) investigated shear transfer in cracked reinforced concrete with $10 \mathrm{~mm}$ gravel aggregate. They obtained very similar crack paths, with $\left(w-w_{0}\right) / s \sim 0.5$, in their tests with bonded and unbonded reinforcement, which is at odds with the findings of Walraven and Reinhardt (1981). More recently, Mansur et al. (2008) carried out a series of push-off tests on high-strength concrete specimens with $20 \mathrm{~mm}$ crushed granite aggregate and embedded stirrups. In that work, $\left(w-w_{0}\right) / s$ appears to be similar to that in the current tests.

Figures 6(a) and 6(b) show the relationship between shear stress and slip in the limestone (PL) and gravel (PG) specimens, respectively. The load decreased to $70 \%$ of its peak value at a slip of around $7 \mathrm{~mm}$ slip in the PL tests. The response in the PG tests was similar. Figure 7 (a) shows that the initial shear stiffnesses were similar in the first load cycle $\left(E_{\mathrm{g}}=\tau / s, \tau\right.$ is shear stress) of tests PL2, PL3, PG3 and PL4 in which the initial crack widths were similar. The relatively low initial stiffness in test PG2 is attributable to the greater initial crack width of $0.27 \mathrm{~mm}$. Figures 7(b)-7(e) compare the relationship between shear stress and incremental slip in successive load cycles of the tests on P2 and $\mathrm{P} 3$ specimens. The figures show that the shear stiffness of the limestone specimens (but not the gravel specimens) remained fairly constant between successive load cycles despite the increase in crack width between load cycles. Figures 7(d) and 7(e) show that the difference in response is most noticeable for specimens PL3 and PG3.

The high shear strength of the limestone specimens is thought to be due to interlocking at the macro-level (see Figure 8), which would also explain the relatively constant value of the aggregate interlock stiffness observed in the PL tests at different load cycles. Walraven and Al-Zubi (1995) observed similar interlocking at the macro-level in lightweight aggregate slender beams with stirrups tested in shear. They reported that the irregular shape of the crack surfaces allowed contact areas to develop despite the aggregate particles fracturing completely at cracks. 
Influence of aggregate fracture on shear transfer through cracks in reinforced

concrete

Sagaseta and Vollum

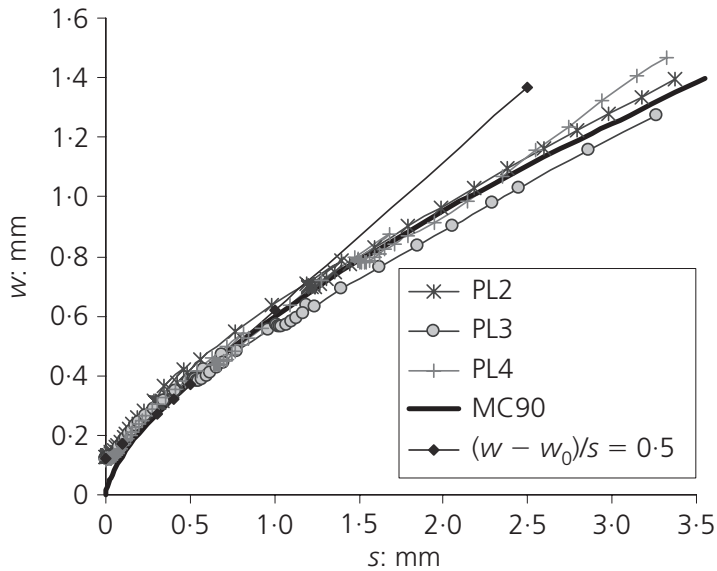

(a)

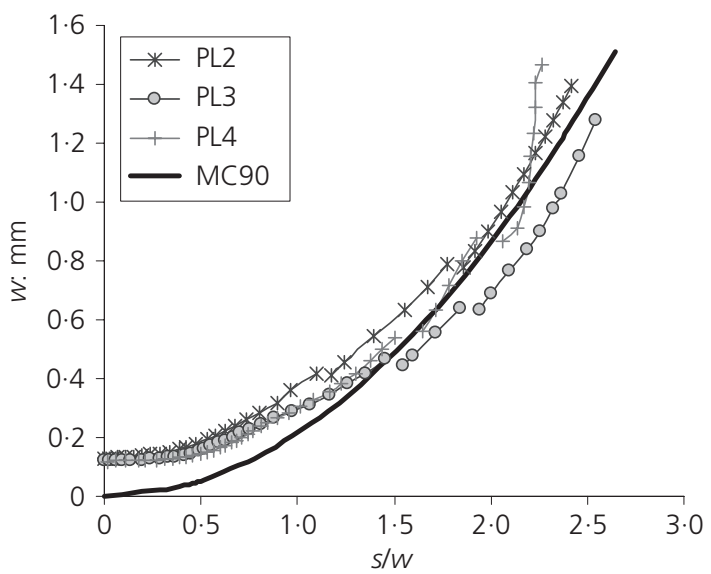

(c)

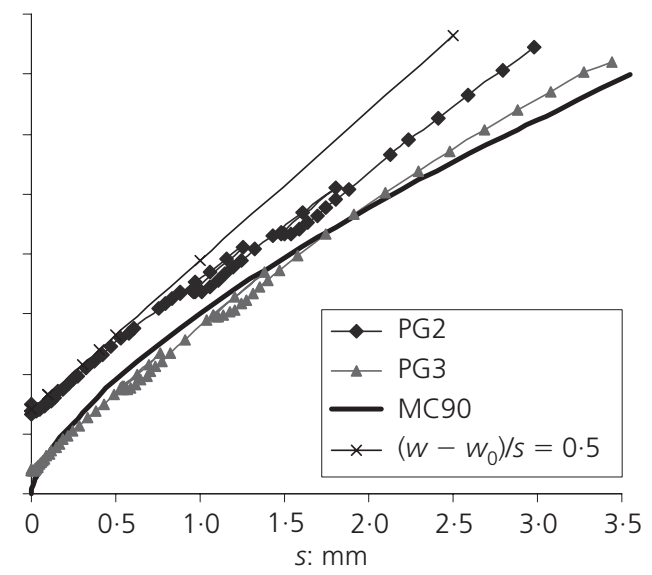

(b)

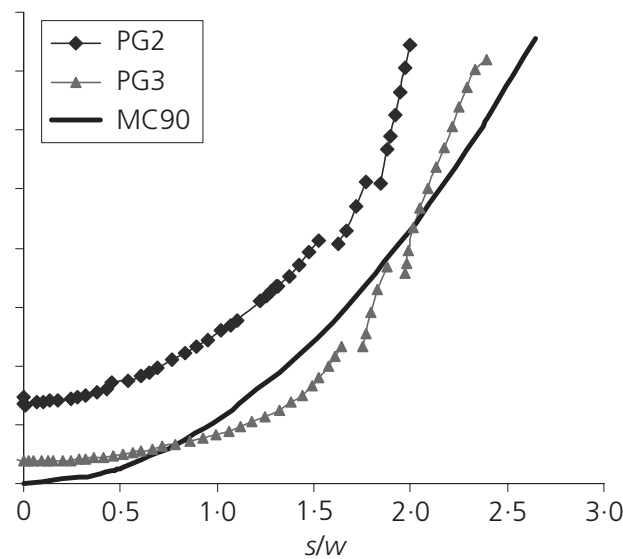

(d)

Figure 5. Relative crack displacements from Demec measurements: (a) crack path in PL tests; (b) crack path in PG tests; (c) $w-s / w$ relationship in PL tests; (d) $w-s / w$ relationship in $P G$ tests

\section{Stirrup strains}

Figure 9 shows the increments in stirrup strain due to crack dilation during the first load cycle. The Demec readings were similar over each stirrup within a specimen and, as expected, less than the corresponding strain gauge measurements in the reinforcement at the crack, which were more variable. Where measured, the strains were also similar in opposite legs of the same stirrup (PL2: SG5-6 and SG7-8). Strains were almost zero in the strain gauges $100 \mathrm{~mm}$ from the crack plane in specimens PL2 and PL3. The relationship between the reinforcement strain at cracks and the Demec strains, which are averaged over a gauge length of $150 \mathrm{~mm}$, depends on the strain distribution within the stirrups, which in turn depends on the bond stress distribution. For example, the ratio between the peak strain in the reinforcement at the crack and the mean strain measured by the Demec gauge is 2.29 if the strain varies parabolically from a maximum at the crack to zero $100 \mathrm{~mm}$ from the crack. The corresponding ratio is 1.6 for a linear variation in strain. The ratio between the
Demec and strain gauge readings in Figure 9 typically lies between these limits. The crack width at which the stirrups yielded is uncertain since strains were only measured in the stirrups after the specimens had been pre-cracked. The stirrups are estimated to have yielded towards the end of the first load cycle when the crack widths were between 0.3 and $0.5 \mathrm{~mm}$.

\section{Analysis of test results}

\section{Comparison with analytical models for aggregate interlock}

Walraven and Reinhardt (1981) investigated shear transfer through pre-cracked push-off specimens with external restraint and embedded stirrups. They found significant differences between the response of the two types of specimens, which they attributed to the presence of dowel action and bond stresses in the specimens with embedded stirrups. They estimated the contribution of dowel action analytically and concluded that it was 
Magazine of Concrete Research Volume 63 Issue 2
Influence of aggregate fracture on shear transfer through cracks in reinforced

concrete

Sagaseta and Vollum

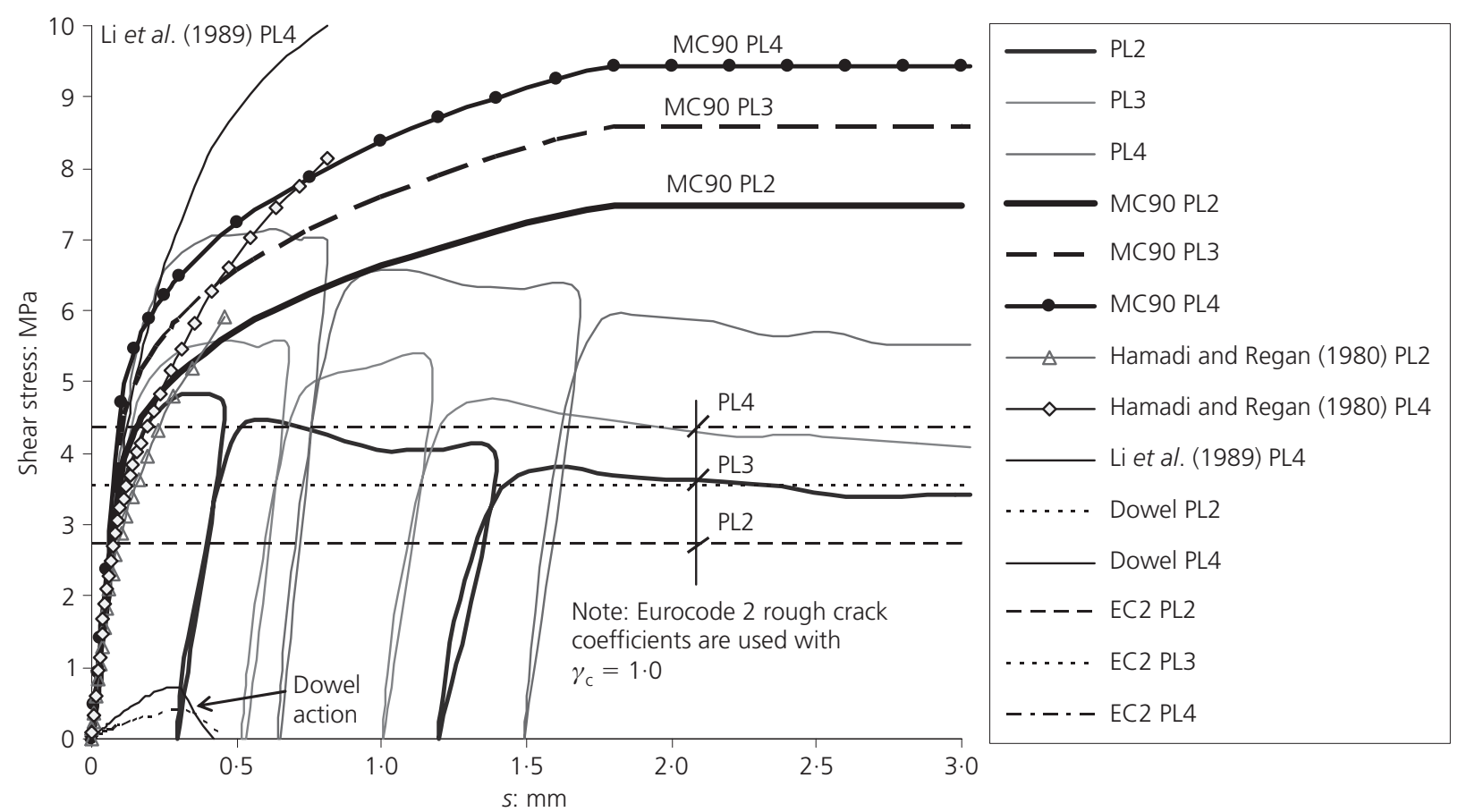

(a)

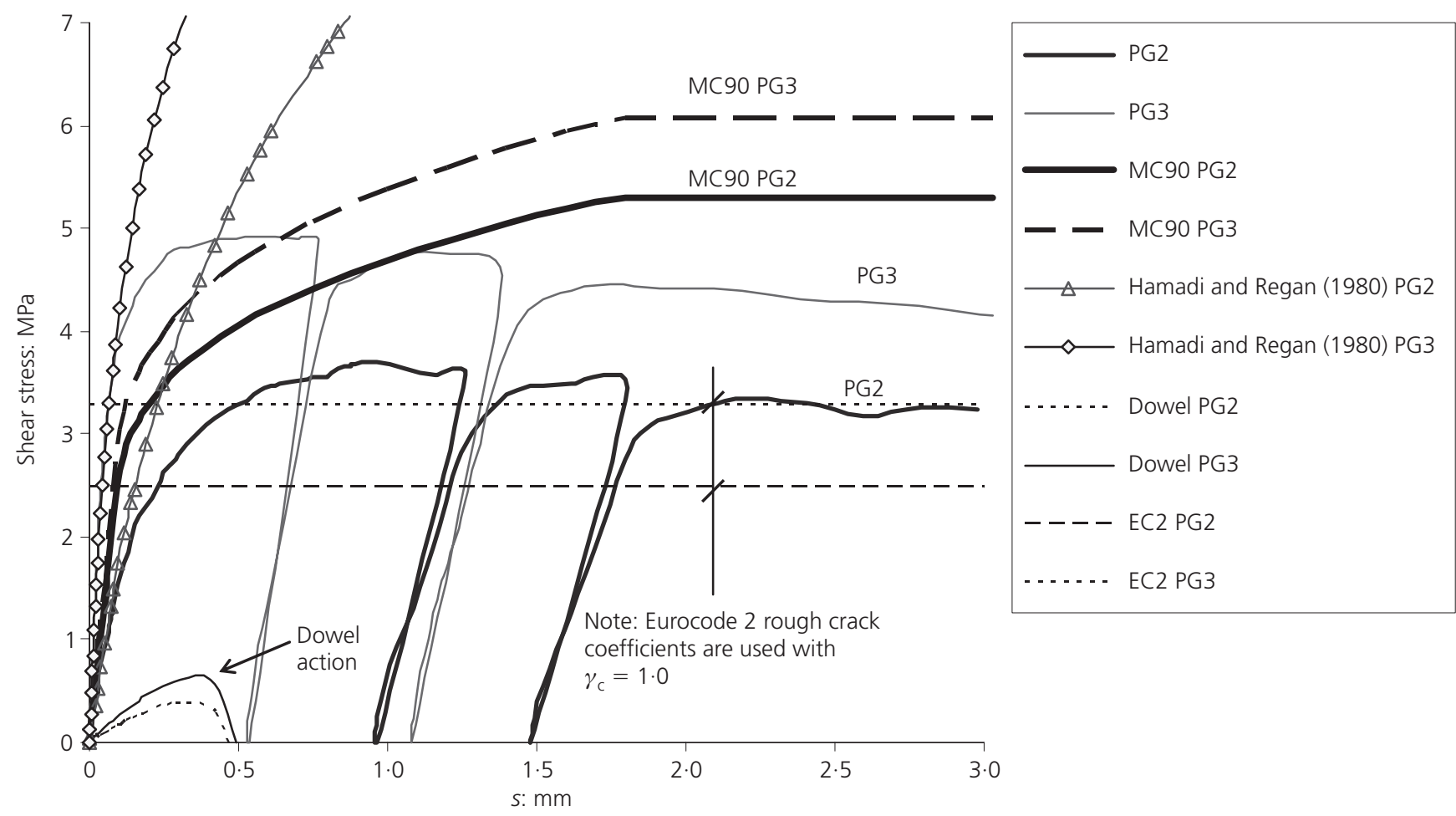

(b)

Figure 6. Comparison of measured shear stresses with predictions of MC90 (CEB-FIP, 1990), Li et al. (1989) and Hamadi and Regan (1980) (Equation 4, $k=5.0 \mathrm{MPa}$ ) for (a) limestone specimens and (b) gravel specimens 


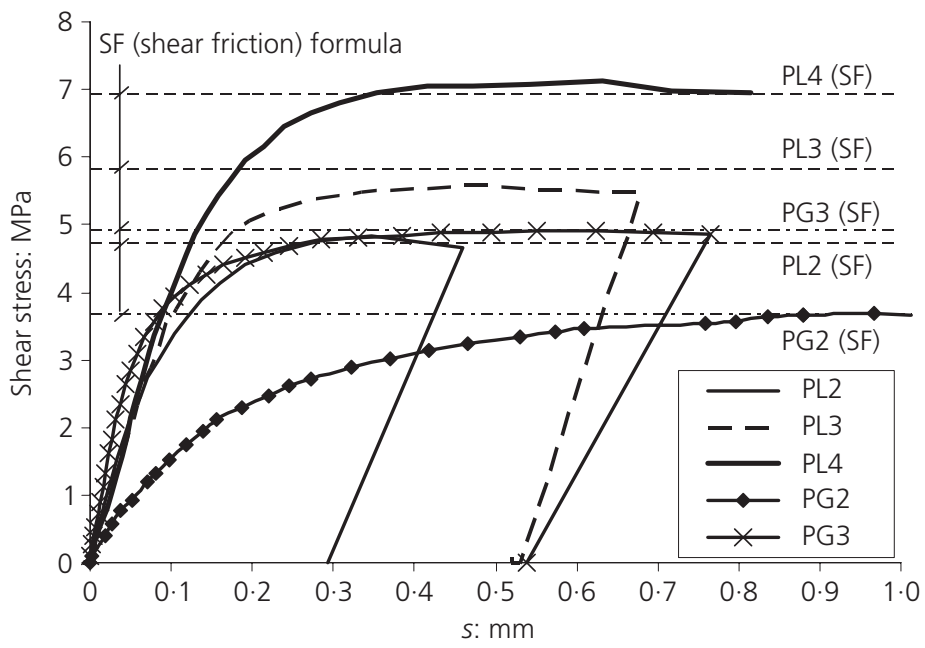

(a)

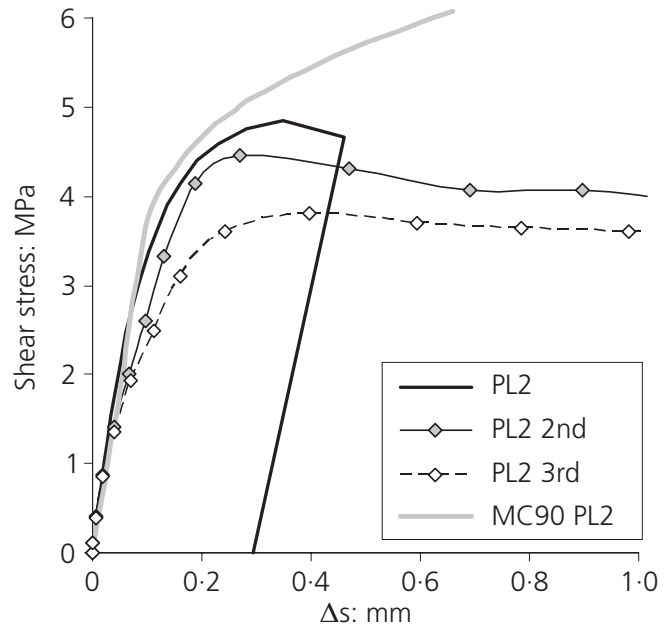

(b)

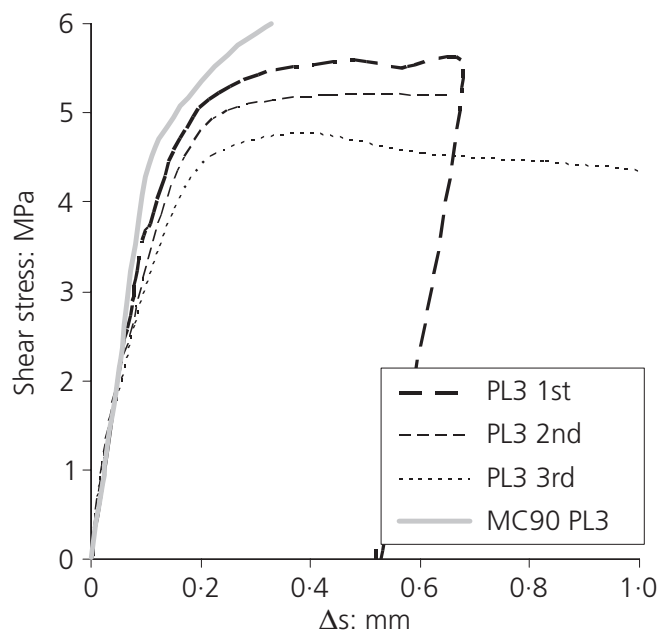

(d)

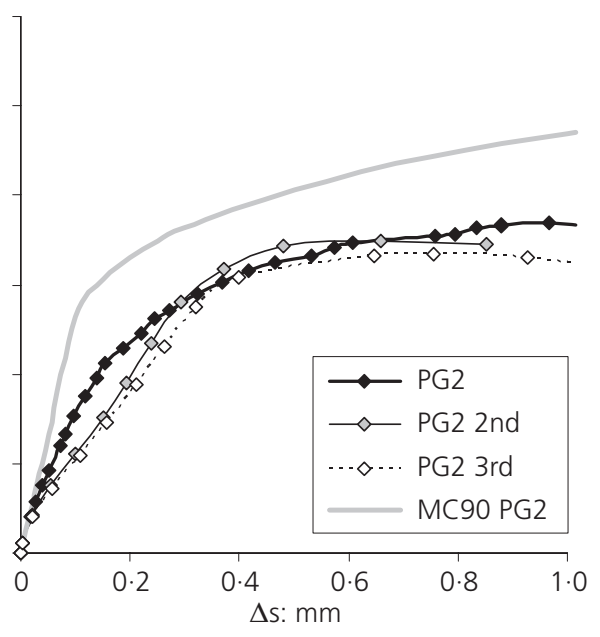

(c)

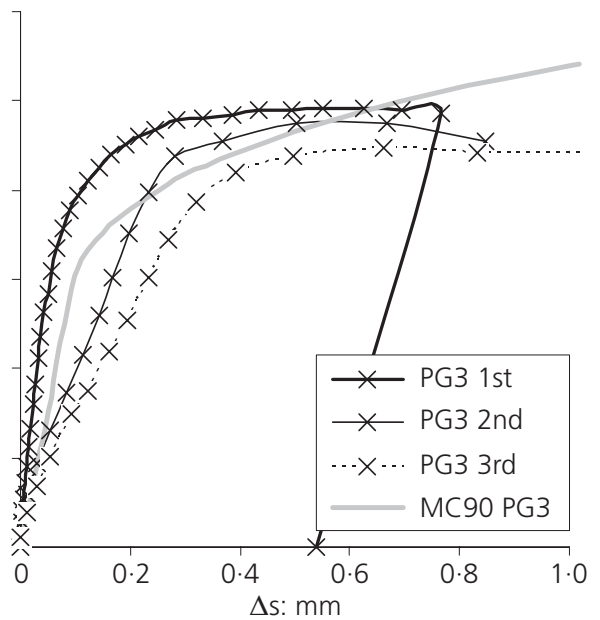

(e)

Figure 7. Shear stiffness of push-off tests: (a) stresses developed in first load cycle; (b) stresses in all load cycles for PL2; (c) stresses in all load cycles for PG2; (d) stresses in all load cycles for PL3; (e) stresses in all load cycles for PG3 
Influence of aggregate fracture on shear transfer through cracks in reinforced

concrete

Sagaseta and Vollum

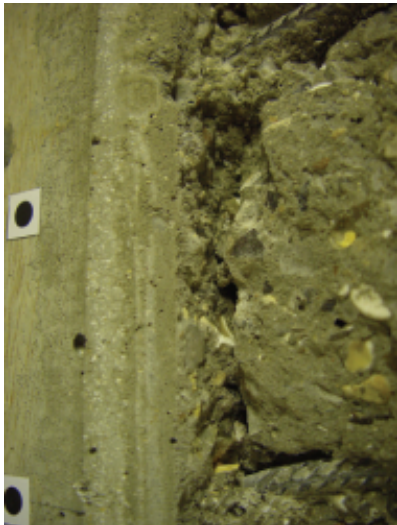

(a)

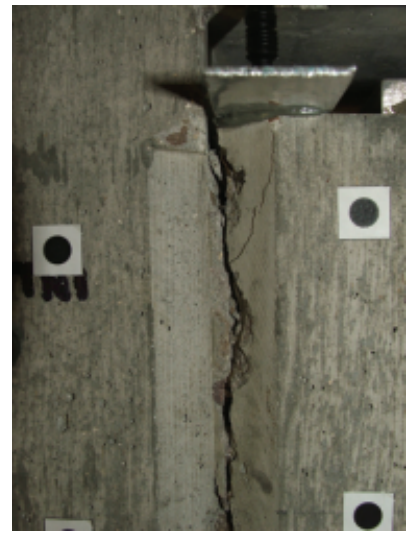

(b)
Figure 8. Crack roughness: (a) gravel specimen (crack-level); (b) limestone specimen (macro-level)

relatively insignificant. They found that the crack path $w-s$ was sensitive to the restraint stiffness in externally restrained specimens but almost independent of the stirrup ratio in specimens with embedded stirrups. They concluded that the presence of bond stresses in specimens with embedded stirrups

(a) reduces the crack width in the vicinity of reinforcement bars

(b) increases the tensile force in the stirrups over and above that arising from crack dilatancy in similar specimens with external stirrups.

They speculated that the reduction in crack width adjacent to the reinforcement bars allows secondary struts to form, which are equilibrated by an additional tensile force in the stirrups. Walraven and Reinhardt (1981) found the contribution of the secondary struts to be negligible when the reinforcement ratio $\rho_{\mathrm{v}}=100 n A_{\mathrm{sw}} /\left(b_{\mathrm{cr}} H_{\mathrm{cr}}\right)$ was below $0 \cdot 56 \%$ or if $\delta w>>\delta s$ where $\delta w$ and $\delta s$ are incremental values. The reinforcement ratios in the authors' tests were $0.42,0.63$ and 0.85 , which suggests that shear was principally transferred through aggregate interlock in the specimens with $2 \mathrm{~T} 8$ stirrups with secondary struts contributing to the shear strength of specimens with three and four stirrups.

Walraven and Reinhardt's (1981) observations are at odds with those of Millard and Johnson (1985) who obtained good estimates of the shear-slip response of their specimens, in which the reinforcement ratio varied between 0.33 and $1 \cdot 34 \%$, by simply combining the contributions of dowel action and aggregate interlock. They calculated the contribution of dowel action using a model derived from the classical solution for a beam on an elastic foundation and used Walraven and Reinhardt's (1981) twophase model to assess the contribution of aggregate interlock. Interestingly, they found that the crack width in their specimens remained almost constant beneath the surface of the concrete.

The present authors estimated the contribution of dowel action in their tests with Millard and Johnson's (1984) model. The results are shown in Figure 10, which shows that the contribution of dowel action can be neglected for practical purposes. The authors went on to compare the shear-slip responses measured in their tests with the predictions of the following five commonly used crack dilatancy models.

(a) MC90 (CEB-FIP, 1990) equations for aggregate interlock

$$
\begin{aligned}
& \text { For } s<0.1 \mathrm{~mm} \\
& \text { 1. } \tau_{\mathrm{cr}}=5 \tau_{\mathrm{ult}} s
\end{aligned}
$$

For $s \geqslant 0 \cdot 1 \mathrm{~mm}$

$$
\text { 2. }\left[\frac{\tau_{\mathrm{cr}}}{\tau_{\mathrm{ult}}}\right]^{4}-0.5\left[\frac{\tau_{\mathrm{cr}}}{\tau_{\mathrm{ult}}}\right]^{3}=0 \cdot 3 s-0.03
$$

where $\tau_{\text {ult }}=0 \cdot 4 f_{\mathrm{c}}^{\prime 2 / 3} \sigma_{\text {ncr }}^{1 / 3}$

Crack dilatancy

$$
\text { 3. } w=0 \cdot 6 s^{2 / 3}
$$

(b) Hamadi and Regan (1980)

$$
\text { 4. } \tau_{\mathrm{cr}}=k \frac{s}{w}=k r
$$

5. $\tau_{\mathrm{cr}} \leqslant \tau_{\mathrm{ult}}=C+\mu \sigma_{\mathrm{ncr}}$

where $k$ equals $5 \cdot 4 \mathrm{~N} / \mathrm{mm}^{2}$ for gravel aggregate and $2 \cdot 7 \mathrm{~N} /$ $\mathrm{mm}^{2}$ for expanded clay aggregate.

(c) Linear aggregate interlock relationship (Walraven and Reinhardt, 1981)

$$
\sigma_{\mathrm{ncr}}=-\frac{f_{\mathrm{cu}}}{20}
$$

$$
+\left[1 \cdot 35 w^{-0 \cdot 63}+\left(0 \cdot 191 w^{-0 \cdot 552}-0 \cdot 15\right) f_{\mathrm{cu}}\right] s
$$

$$
\begin{aligned}
\tau_{\mathrm{cr}}= & -\frac{f_{\mathrm{cu}}}{30} \\
& +\left[1.8 w^{-0.80}+\left(0.234 w^{-0.707}-0.20\right) f_{\mathrm{cu}}\right] s
\end{aligned}
$$




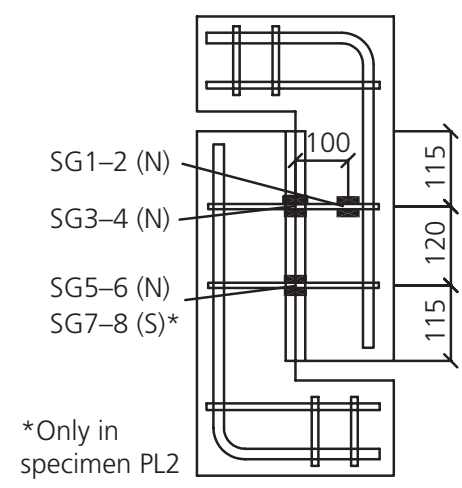

(a)

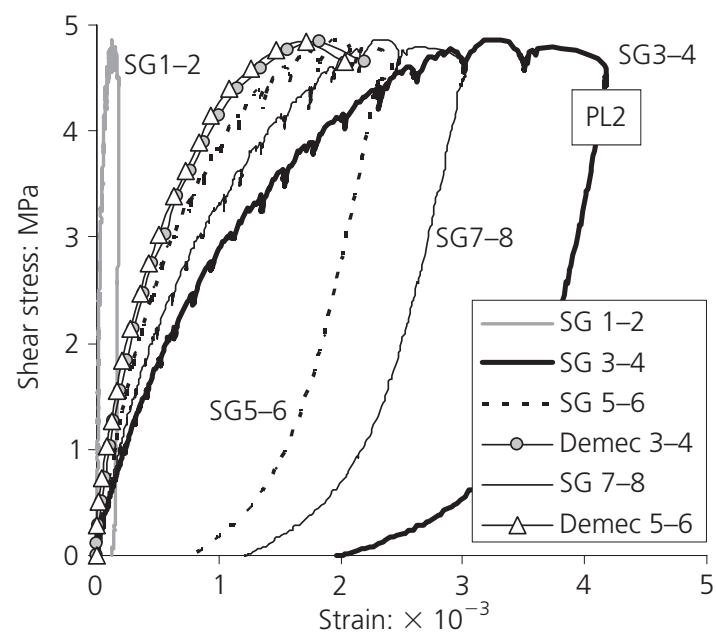

(b)

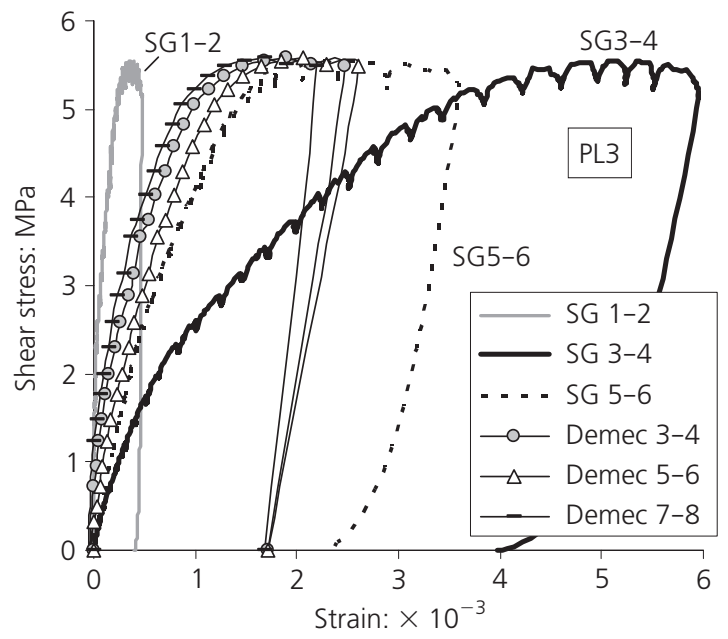

(d)

Figure 9. Strain in shear reinforcement in push-off tests P2 and P3 (first cycle): (a) location of strain gauges; (b) strain measurements for PL2; (c) strain measurements for PG2; (d) strain measurements for PL3; (e) strain measurements for PG3 (the numbering of the Demec gauges relates to strain gauge (SG))
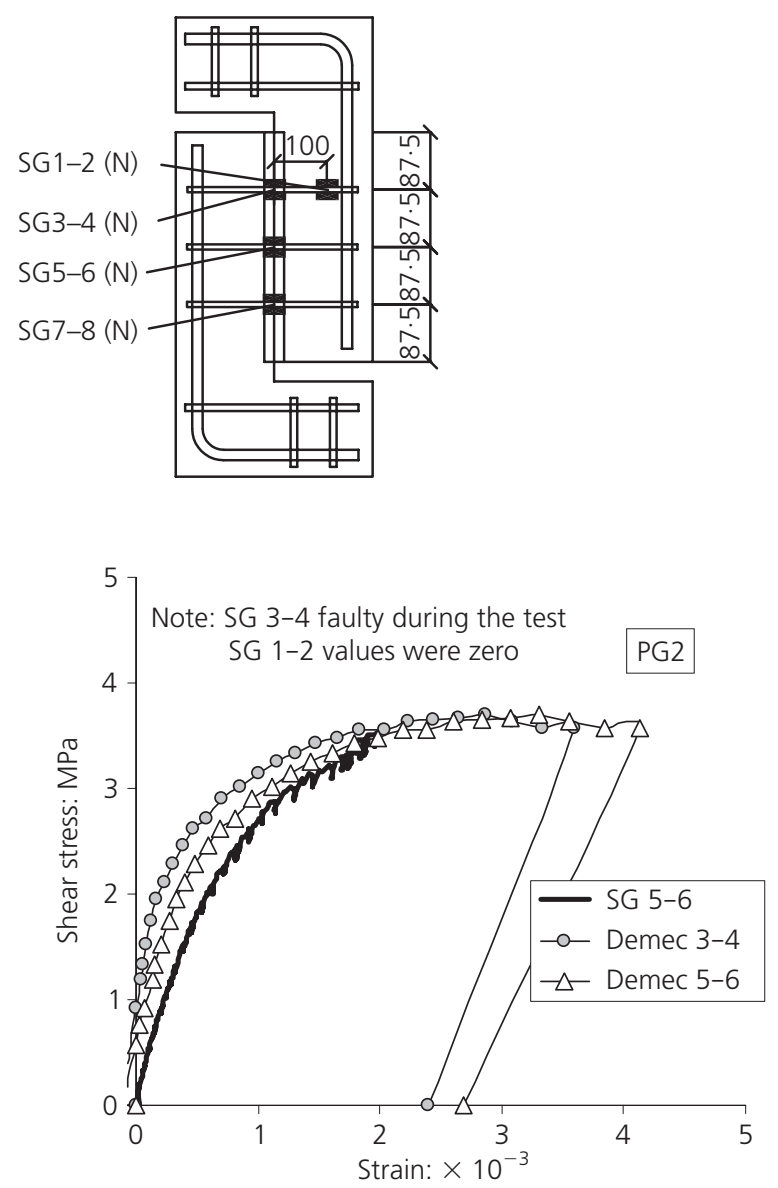

(c)

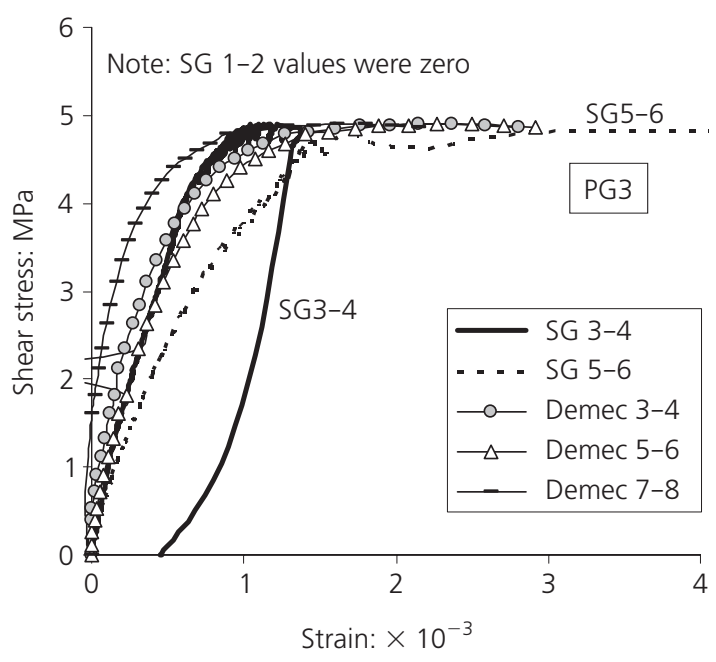

(e) 
Magazine of Concrete Research Volume 63 Issue 2
Influence of aggregate fracture on shear transfer through cracks in reinforced concrete

Sagaseta and Vollum

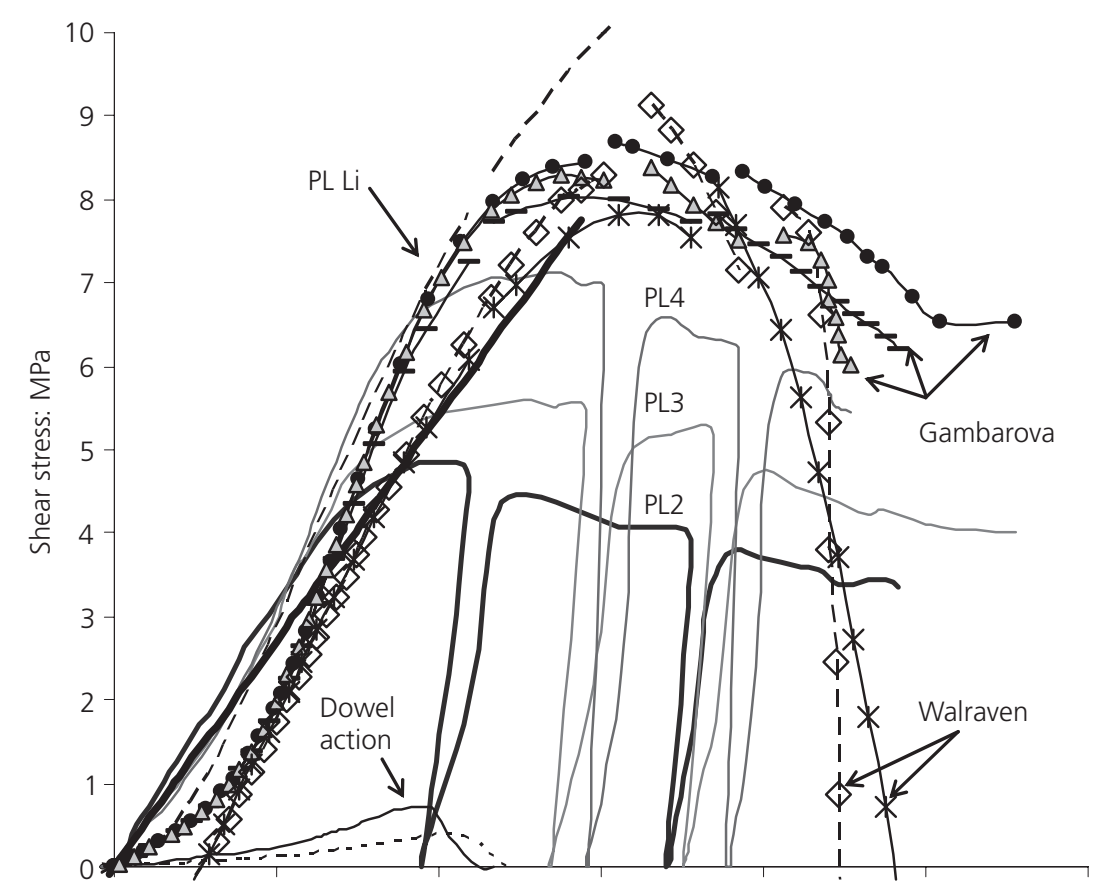

(a)

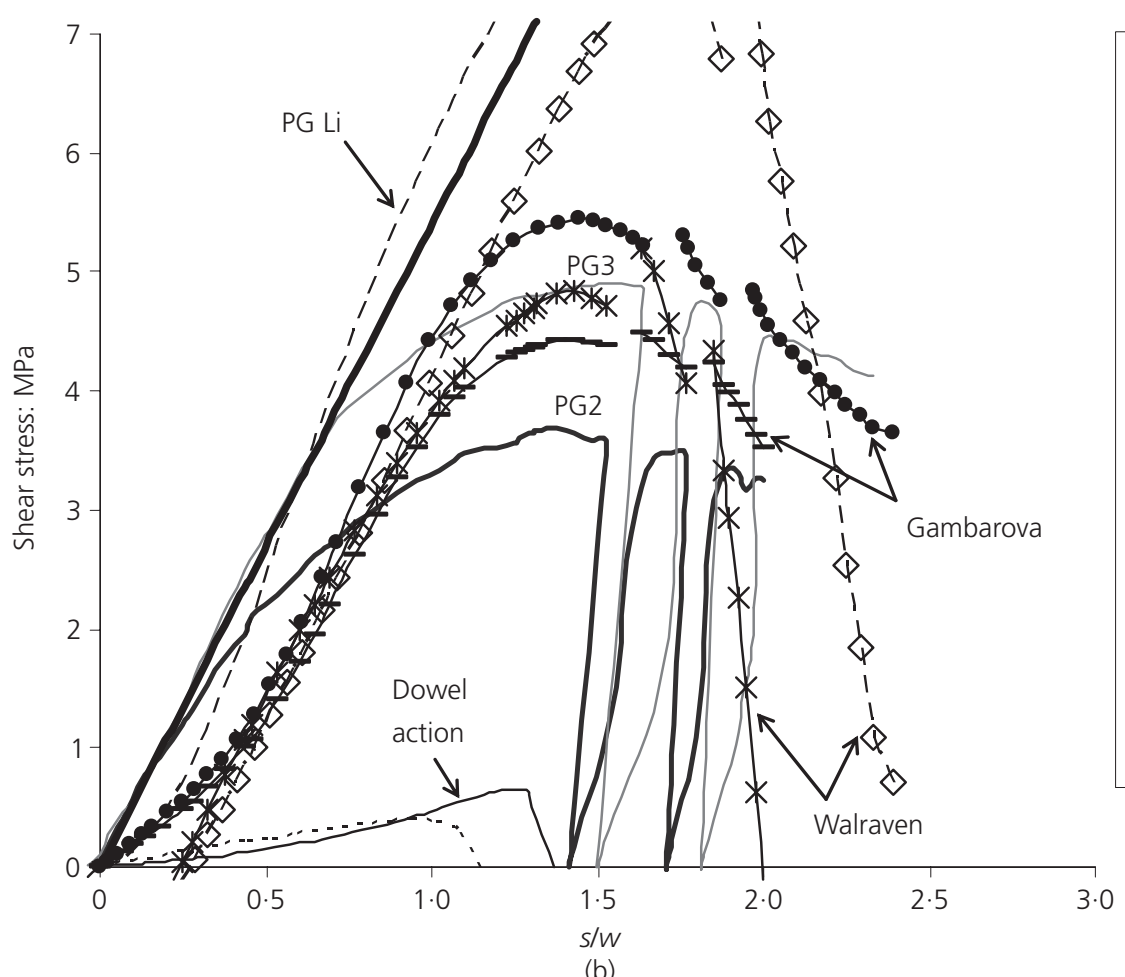

(b)
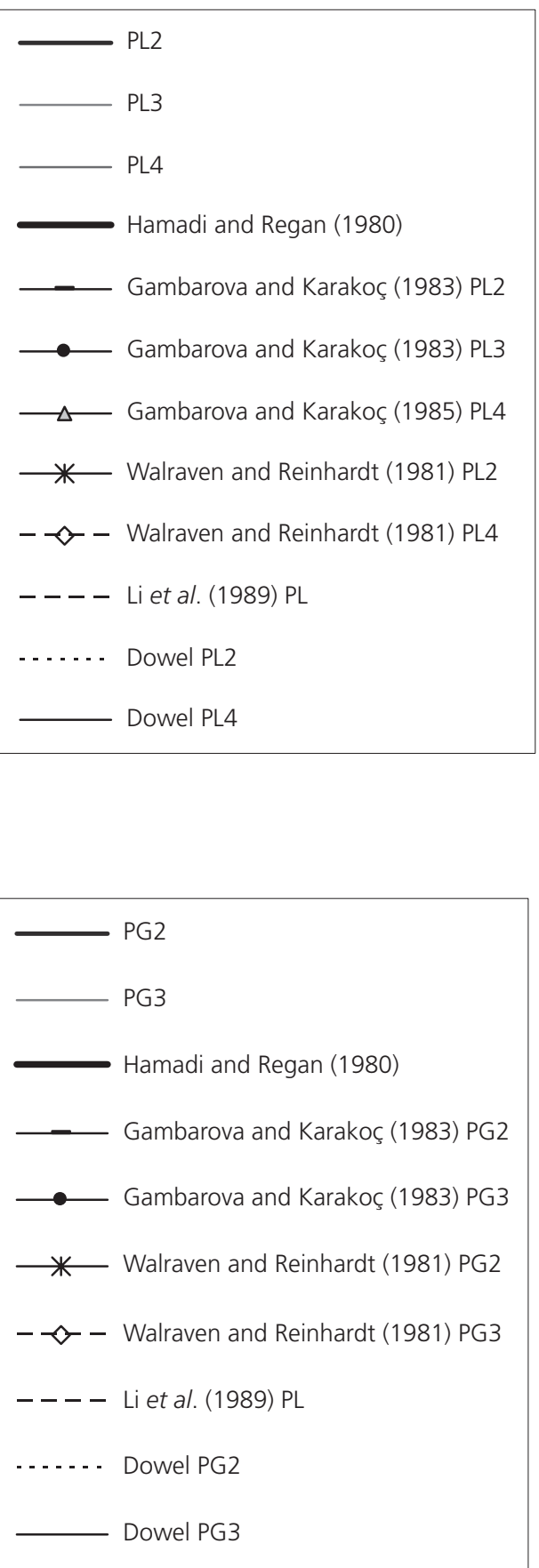

Figure 10. Experimental and predicted shear stresses in tested specimens: (a) PL2 to PL4; (b) PG2 and PG3 
(d) Rough crack model (Gambarova and Karakoç, 1983)

$$
\text { 8. } \sigma_{\text {ncr }}=k_{1} k_{2} \sqrt{w} \frac{r}{\left(1+r^{2}\right)^{0 \cdot 25}} \tau_{\mathrm{cr}}
$$

$$
\text { 9. } \tau_{\mathrm{cr}}=\tau_{0}\left[1-\left(\frac{2 w}{a}\right)^{1 / 2}\right] r \frac{k_{3}+k_{4}|r|^{3}}{1+k_{4} r^{4}}
$$

where $r=s / w, a$ is maximum aggregate size, $k_{1} k_{2}=0.62$, $k_{3}=2 \cdot 45 / \tau_{0}, k_{4}=2 \cdot 44\left(1-\left(4 / \tau_{0}\right)\right)$ and $\tau_{0}=0 \cdot 25 f_{\mathrm{c}}^{\prime}$

(e) Simplified method based on the contact density theory (Li et al., 1989)

10. $\sigma_{\mathrm{ncr}}=3 \cdot 83 f_{\mathrm{c}}^{\prime 1 / 3}\left[\frac{\pi}{2}-\cot ^{-1} r-\frac{r}{1+r^{2}}\right]$

11. $\tau_{\mathrm{cr}}=3 \cdot 83 f_{\mathrm{c}}^{\prime 1 / 3} \frac{r^{2}}{1+r^{2}}$

Theoretically, models $(a)$ to $(e)$ should underestimate the shear strength of the tested specimens since they only model shear transfer through aggregate interlock and not dowel or secondary truss action. Models $(a)$ and $(b)$ calculate the ultimate shear resistance in terms of the maximum crack normal stress $\sigma_{\text {ncr }}$, which depends on the yield capacity of the stirrups, unlike models $(c)$ to $(e)$ in which the shear stress is assumed to depend solely on the crack path $w-s$. Models $(d)$ and $(e)$ are based on theoretical considerations while the other models are essentially empirical. Only model $(d)$ accounts for the influence of the maximum aggregate size on shear transfer, which is debatable as discussed by Millard and Johnson (1986). Figure 5 shows that the crack paths were almost identical in tests PL2, PL3 and PL4 which, according to models $(c)$ to $(e)$, implies that the contribution of aggregate interlock was similar in each test. Figure 6 suggests that, in reality, the shear strength depends on the maximum clamping stress provided by the stirrups as assumed in models $(a)$ and $(b)$. The increased shear resistance of PL3 and PL4, compared with PL2, can be explained in terms of shear friction or the secondary truss action described by Walraven and Reinhardt (1981) since the crack paths were similar. The increase in shear strength $\Delta F$ of PL3 and PL4 over PL2 due to the truss action described by Walraven and Reinhardt (1981) is given by

12. $\Delta F=\Delta T_{\mathrm{s}} \frac{\delta w}{\delta s}$

where $\Delta T_{\mathrm{s}}=(n-2) A_{\mathrm{sw}} f_{\mathrm{y}} \cdot 10^{-3} \mathrm{kN}$ where $n$ is the total number of stirrups, $A_{\mathrm{sw}}$ is the area of both legs of each T8 stirrup and $f_{\mathrm{y}}$ is the yield strength of the stirrups (in $\mathrm{MPa}$ ). $\delta w / \delta s$ is normal to the crack opening direction. $\Delta F$ was calculated for PL3 and PL4 and was found to be $0.5 \Delta T_{\mathrm{s}}=28 \mathrm{kN}$ for PL3 and $55 \mathrm{kN}$ for PL4; the measured increases in shear strength were $33 \mathrm{kN}$ and $73 \mathrm{kN}$, respectively.

Models $(a)$ to $(e)$ were used to calculate the crack stresses in the tested specimens in terms of the measured crack displacements. The results of the analyses are shown in Figures 6, 7, 10 and 11. Figures 6 and 7 show that MC90 predicts the measured shear stresses reasonably well up to the peak load in the first load cycle but subsequently overestimates the stresses. Figure 5 shows that Equation 3 from MC90 gives good predictions of the measured crack displacements in all the tests except PG2 in which the initial crack width was relatively wide at $0 \cdot 27 \mathrm{~mm}$. Figures 6 and 10 show that Equation 4 (Hamadi and Regan, 1980) gives good estimates of the initial stiffness of the PL and PG specimens. Figure 10 also shows that models $(c)$ to $(e)$ overestimate the shear strength of the tested specimens and that the accuracy of the models tends to improve with increasing numbers of stirrups. The models of Walraven and Reinhardt (1981) and Gambarova and Karakoç (1983) underestimate the measured crack shear stresses when $s / w<0.7$ and overestimate stresses subsequently. The Gambarova and Karakoç (1983) model gives better estimates of the peak shear strengths of the PL specimens if the maximum aggregate size is reduced to $3 \mathrm{~mm}$ but the reduction in residual strength with increasing crack width is overestimated. Analysis (Sagaseta, 2008) shows that Walraven and Reinhardt's (1981) equations for lightweight concrete significantly underestimate the shear strength of the tested specimens.

Figure 11 compares predicted crack normal stresses with normal stresses calculated in terms of the mean strains measured in the stirrups at the crack plane. The normal stress was calculated in terms of the Demec strains in test PG2 subsequent to the failure of the strain gauges. Li et al.'s (1989) model predicts the crack normal stresses reasonably well in the PL specimens prior to yielding of the stirrups, but overestimates the stresses in the PG specimens. The models of Walraven and Reinhardt (1981) and Gambarova and Karakoç (1983) underestimate the crack normal stress prior to the stirrups yielding, as found by Walraven and Reinhardt (1981), and overestimate stresses subsequently. Analysis shows that the crack dilation would need to be significantly greater than measured for models $(c)$ to $(e)$ to correctly predict the $\tau-S$ response of the tested specimens.

\section{Shear friction formulae}

Design codes such as Eurocode 2 (BSI, 2004) and ACI-318-08 (ACI, 2008) define the maximum shear stress that can be transferred through aggregate interlock in terms of the Coulomb failure criteria $\left(\tau=C+\mu \sigma_{\text {ncr }}\right)$. These 'shear friction' equations are typically used in the design of construction joints, but can be used to examine shear transfer along cracks in reinforced concrete members. The cohesion factor $C$ is usually defined in terms of the 

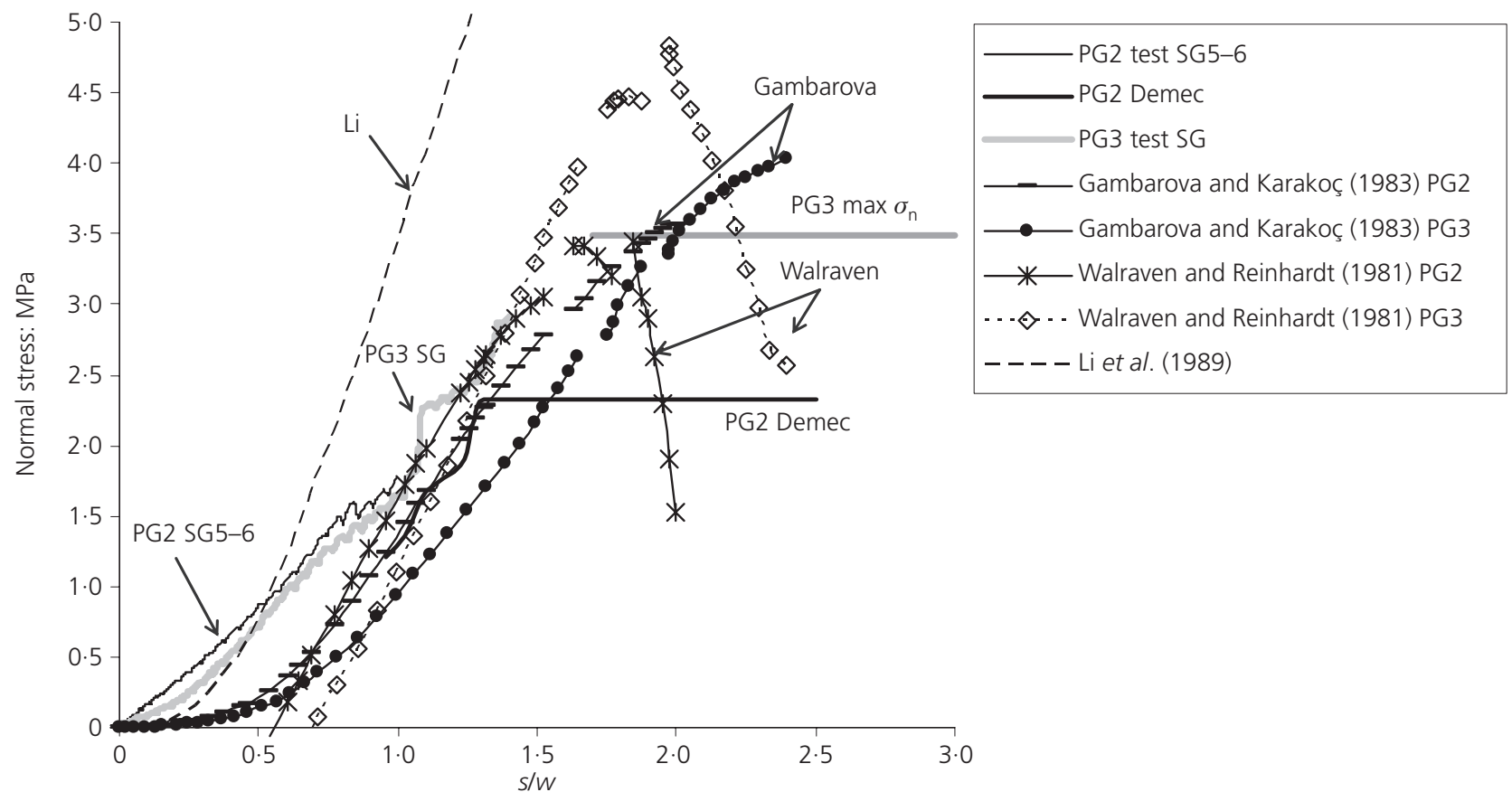

(a)
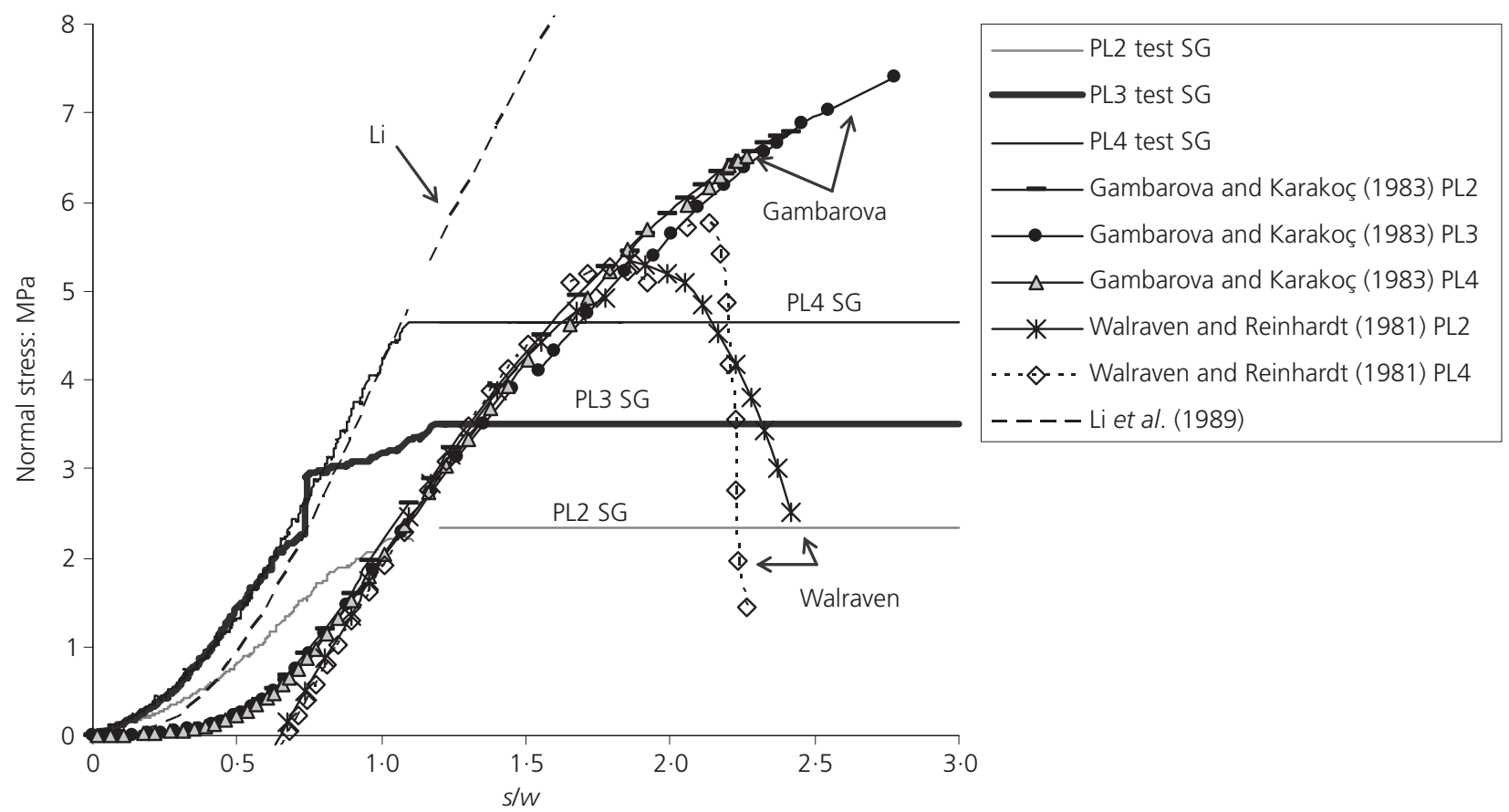

Figure 11. Experimental and predicted normal stresses in specimens: (a) PG2 and PG3; (b) PL2 to PL4

concrete tensile strength and the coefficient of friction $\mu$ is related to the roughness of the interface. Table 4 shows that there are large variations in the values of $C$ and $\mu$ recommended in the literature. Figure 6 shows that the shear strength of the tested specimens is significantly underestimated by the Eurocode 2 rough shear friction coefficients for slips up to at least $3 \mathrm{~mm}$. The ultimate crack normal stress $\left(\sigma_{\text {ncru }}=\rho_{\mathrm{v}} f_{\mathrm{y}}\right.$ where $\left.\rho_{\mathrm{v}}=n A_{\mathrm{sw}} / b_{\mathrm{cr}} H_{\text {cr }}\right)$ was calculated with $f_{\mathrm{y}}=550 \mathrm{MPa}$ in the present work, giving $\sigma_{\text {ncru }}=2.33,3.49$ and $4.66 \mathrm{MPa}$ for the tested specimens with two, three and four stirrups, respectively. 


\begin{tabular}{|c|c|c|c|}
\hline & Surface & Cohesion, C & Friction, $\mu$ \\
\hline \multirow{3}{*}{ Eurocode 2 (BSI, 2004) } & Rough & $0.4 f_{\mathrm{ctd}} *$ & 0.70 \\
\hline & Smooth & $0.2 f_{\text {ctd }}$ & 0.60 \\
\hline & Very smooth & $0.025-0.1 f_{\mathrm{ctd}}$ & 0.50 \\
\hline ACl-318-08 (ACl, 2008) & Monolithic & $2.75 \mathrm{MPa}$ & 1.4 \\
\hline \multirow[t]{2}{*}{ (for normal weight concrete) } & Rough & $2.75 \mathrm{MPa}$ & $1 \cdot 0$ \\
\hline & Medium & - & 0.6 \\
\hline \multirow[t]{3}{*}{ Climaco and Regan (2001) } & Rough & $0.25\left(f_{c}^{\prime}\right)^{2 / 3}$ & 1.4 \\
\hline & Medium & $0 \cdot 25\left(f_{c}^{\prime}\right)^{2 / 3}$ & 0.9 \\
\hline & Smooth & $0.5 \mathrm{MPa}$ & 0.7 \\
\hline \multirow[t]{2}{*}{ Hamadi and Regan (1980) } & Natural gravel & 4.0 MPa & 0.7 \\
\hline & Expanded clay & $2.0 \mathrm{MPa}$ & 0.3 \\
\hline \multirow[t]{2}{*}{ Linear regression of push-off test data (PG and PL) } & $\begin{array}{l}\text { Gravel (PG) } \\
\left(f_{c}^{\prime}=31.7 \mathrm{MPa}\right)\end{array}$ & $1.20 \mathrm{MPa}\left(\sim 0.57 f_{\mathrm{ctk}, 0.05}\right)$ & 1.06 \\
\hline & $\begin{array}{l}\text { Limestone }(\mathrm{PL}) \\
\left(f_{c}^{\prime}=53 \cdot 1 \mathrm{MPa}\right)\end{array}$ & $2.50 \mathrm{MPa}\left(\sim 0.91 f_{\mathrm{ctk}, 0.05}\right)$ & 0.95 \\
\hline
\end{tabular}

$* f_{\mathrm{ctd}}=f_{\mathrm{ctk}, 0.05} / \gamma_{\mathrm{c}}$ where $f_{\mathrm{ctk}, 0.05}$ is, in Eurocode 2, the lower characteristic (5\%) concrete tensile strength and $\gamma_{\mathrm{c}}$ is the partial factor for concrete. $\gamma_{\mathrm{c}}=1.5$ for design. $f_{\mathrm{ctk}, 0.05}$ is equal to $0.21\left(f_{\mathrm{c}}^{\prime}\right)^{2 / 3}$ for $f_{\mathrm{c}}^{\prime}<50 \mathrm{MPa}$ and $1.48 \ln \left(1+f_{\mathrm{cm}} / 10\right)$ for $50 \leqslant f_{\mathrm{c}}^{\prime} \leqslant 90 \mathrm{MPa}$

Table 4. Comparison of recommendations for cohesion and friction parameters

A linear regression analysis was used to estimate $\mu$ and $C$ at peak loads in the authors' tests when the crack widths varied between 0.4 and $0.6 \mathrm{~mm}$. The resulting values of $C$ (see Table 4) were normalised by the multiple $1 / f_{\text {ctk }, 0.05}$ (where $f_{\text {ctk }, 0.05}$ (see Table 4) is the lower characteristic (5\%) concrete tensile strength) as in Eurocode 2 (BSI, 2004). Surprisingly, the normalised value of $C$ was greater for the specimens with limestone $(C=0.91)$ than those with gravel aggregate $(C=0.57)$. The values of $C$ and $\mu$ are approximate for the gravel specimens, since only two data points were available. The correlation factor for a linear fit was significant $\left(R^{2}=0.95\right)$ for the limestone tests where three data points were available. Unexpectedly, the values of $\mu$ were similar for both the limestone $(0 \cdot 9)$ and gravel (1.0) specimens, corresponding to a medium-rough surface $(\mu=0 \cdot 9-1)$ according to ACI-318-08 (ACI, 2008) and Climaco and Regan (2001) and greater than the value of 0.7 given in Eurocode 2 for rough cracks. The coefficient of friction in the PL tests was significantly higher than the value of $0 \cdot 3$ measured in the lightweight expanded clay aggregate tests of Hamadi and Regan (1980). Figure 7(a) compares the measured shear strengths with those calculated with the estimated $C$ and $\mu$ coefficients.

\section{Influence of crack width on shear strength}

The shear strength is assumed to be independent of crack width in the shear friction formulae described above, whereas Table 3 shows that specimen PL2b, in which the crack width at peak load was $0.24 \mathrm{~mm}$ compared with $0.36 \mathrm{~mm}$ in PL2 and $0.37 \mathrm{~mm}$ in PL3, resisted a higher peak load than PL2 or PL3. The crack widths at peak load were similar in PL2, PL3 and PL4 in which the peak load increased with the number of stirrups. Figure 6 shows that the shear resistance of the tested specimens reduced with increasing crack width once the stirrups yielded.

Equation 13 is used to calculate the maximum shear stress that can be transferred through cracks in the modified compression field theory (MCFT) of Vecchio and Collins (1986). The equation relates the shear resistance to the crack normal stress $f_{\mathrm{ci}}$ and the current crack width $w$.

13. $\tau=0 \cdot 18 v_{\text {cimax }}+1 \cdot 64 f_{\mathrm{ci}}-0 \cdot 82 \frac{f_{\mathrm{ci}}^{2}}{v_{\mathrm{cimax}}}$

where

$$
v_{\text {cimax }}=\frac{f_{\mathrm{c}}^{\prime 1 / 2}}{0 \cdot 31+24 w /(a+16)}
$$

Figure 12 compares the measured post-peak shear strengths of the PG and PL specimens with the predictions of Equation 13. The crack normal stress in Equation 13 was taken as $f_{\mathrm{ci}}=\rho_{\mathrm{v}} f_{\mathrm{y}}$ (where $\rho_{\mathrm{v}}=n A_{\mathrm{sw}} / b_{\mathrm{cr}} H_{\mathrm{cr}}$ ) in Figure 12 since the stirrups yielded at the end of the first load cycle. Figure 12 shows that Equation 13 predicts the influence of crack width on shear strength reasonably well for specimens PL2 and PL3, but not PL4 if the aggregate diameter $a$ is taken as zero as recommended by Bentz et al. (2006) when the aggregate fractures. 


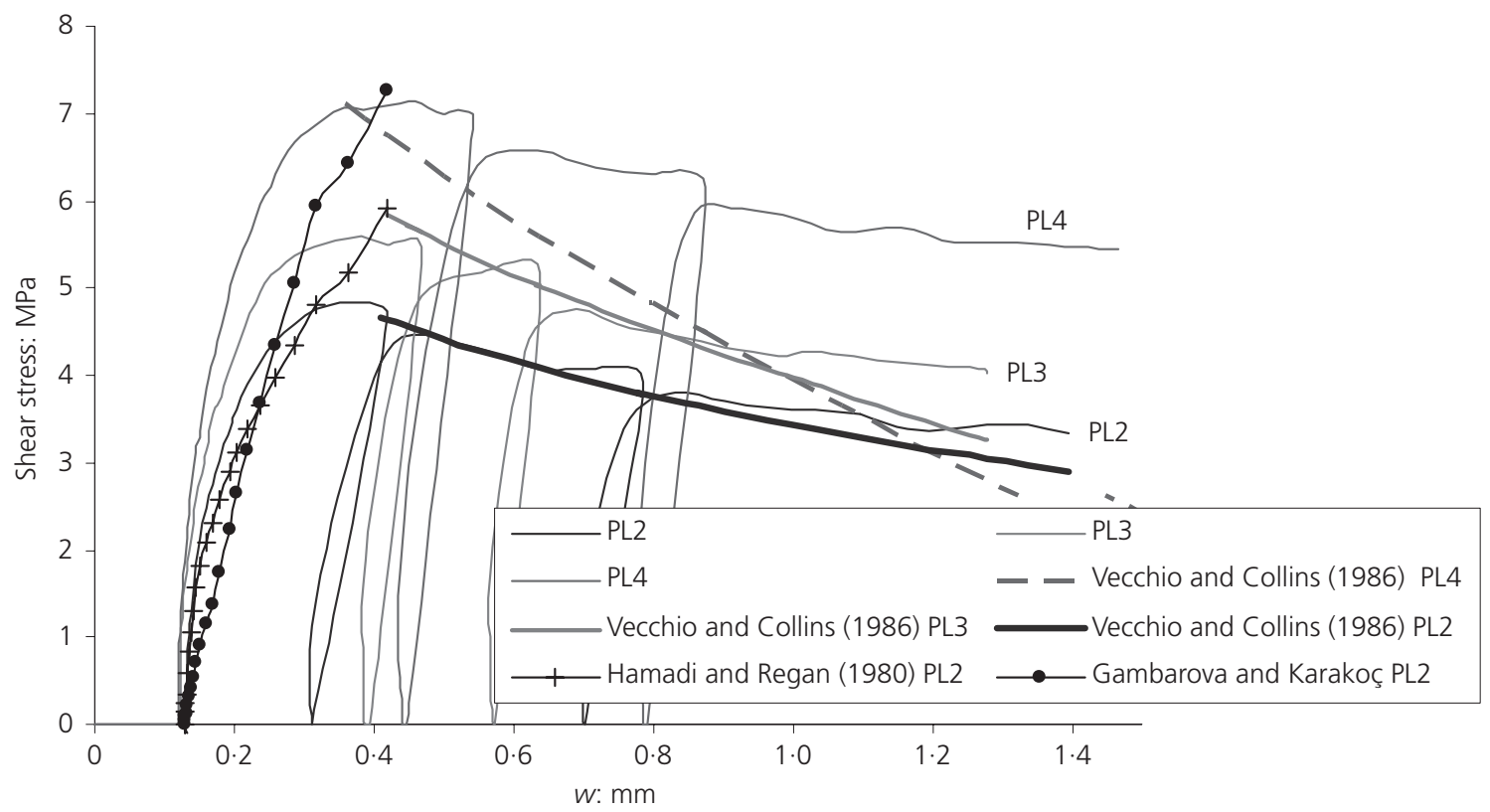

Figure 12. Influence of crack width on shear strength in PL tests

\section{Application of push-off test data to beam tests}

The authors carried out a series of beam tests (Sagaseta, 2008) in parallel with push-off tests to investigate the effect of aggregate fracture on the shear strength of slender and short-span beams. The ratio of the shear span to effective depth was 1.5 in the short-span beams and 3.5 in the slender beams. The beams were made with the same gravel and limestone aggregates as the pushoff specimens. Aggregate fracture was found to reduce only the shear strength of the slender beams without stirrups. Crack opening and sliding displacements were measured at selected cracks in the beams with transducers as shown in Figure 13 to

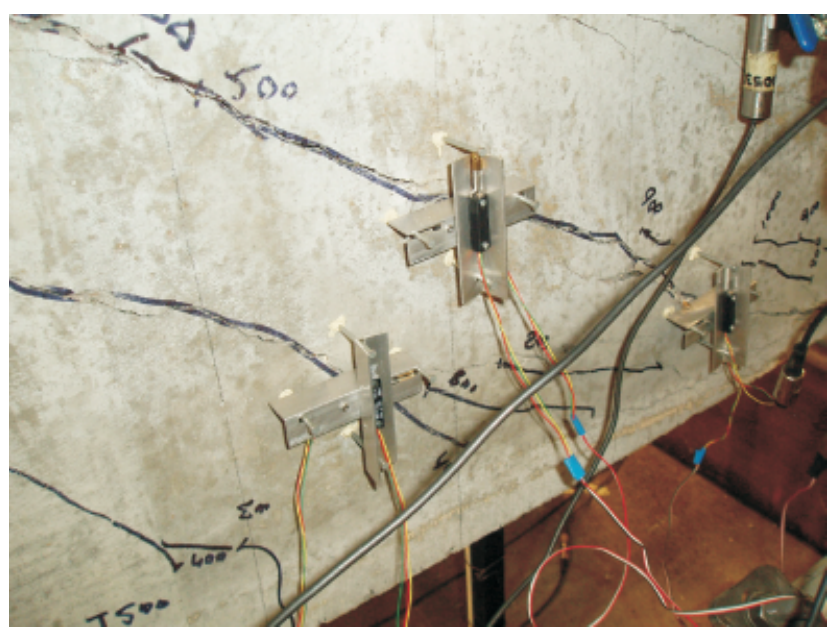

Figure 13. Arrangement of LVDT crosses on shear critical cracks in beams tested by the authors enable shear stresses to be estimated along the cracks. The crack opening and sliding displacements were found to be fairly uniform along the cracks in the beams. Figure 14 shows that the crack paths were quite different in the push-off specimens and the slender beams with stirrups (designated BL1, BL2, BG1 and BG2 where $\mathrm{L}$ denotes limestone and $\mathrm{G}$ gravel). The shear reinforcement ratio ( $\rho_{\mathrm{v}}=100 A_{\mathrm{sw}} / b s$ where $s$ is the stirrup spacing) was $0.5 \%$ in series B1 and $0.83 \%$ in series B2. All the beams were rectangular in cross-section, $500 \mathrm{~mm}$ deep and $135 \mathrm{~mm}$ wide. The difference in crack paths is significant since its influence on the crack shear stress is uncertain. For example, Hamadi and Regan (1980) assume that the shear stress depends solely on $s / w$. On the other hand, Gambarova and Karakoç (1983) relate the crack shear stress to the crack width $w$ in addition to $s / w$, which implies that the results from the push-off tests are not directly applicable to the beam tests since the crack paths were different. A further difficulty in assessing stresses along cracks in beams is that the resultant compressive force normal to the crack plane is not equal and opposite to that in the stirrups as in push-off tests. This is illustrated in Figure 15(a), which compares the resultant forces acting on the crack plane in the beam and push-off tests. The contributions of dowel and secondary truss action (Walraven and Reinhardt, 1981) are omitted from Figure 15(a) for simplicity. Figure 15(b) shows that vertical shear forces are transferred through inclined cracks in beams via the combined contributions of the stirrups (i.e. truss action) and the vertical component of the normal and tangential stress resultants acting on the crack. Figure 15(a) shows that the contribution of the crack shear stress to shear resistance is reduced by the stress $\sigma_{\text {ncr }}$ acting normal to the crack. The net increase in shear resistance due to the normal and tangential stresses acting on a crack inclined at an angle $\theta$ to the horizontal is given by 


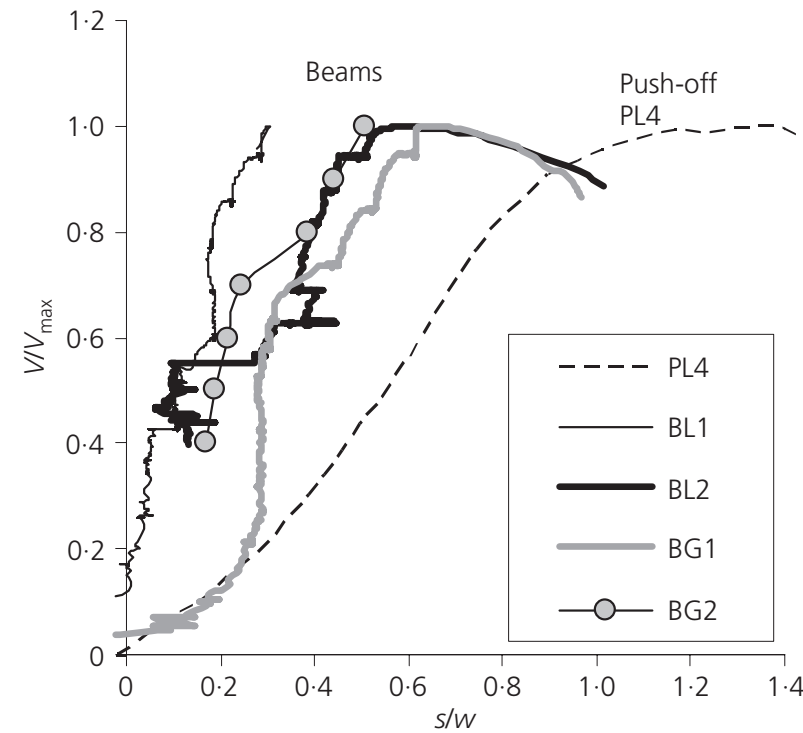

(a)

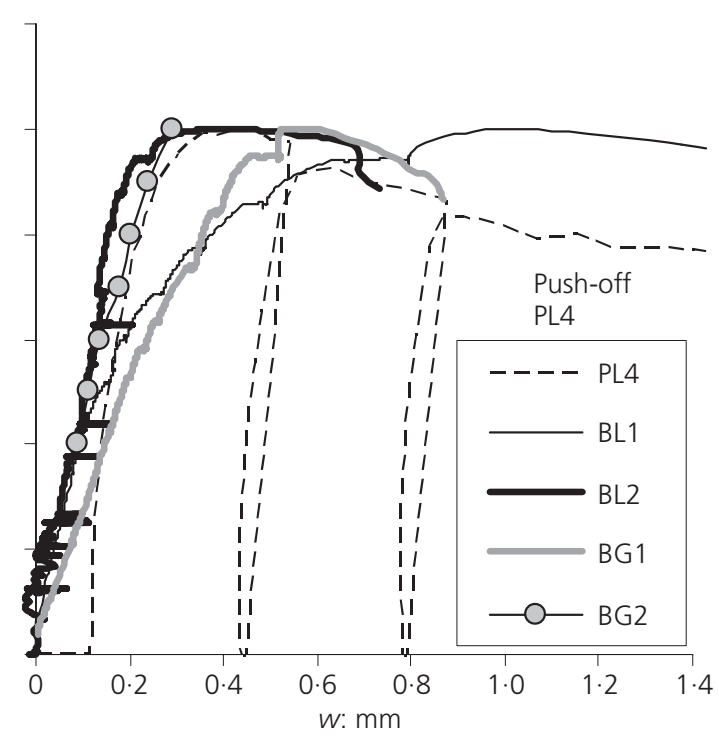

(b)

Figure 14. Comparison between crack paths in slender beams with stirrups (beams B (Sagaseta, 2008)) and push-off tests (PL4):

(a) $s / w$; (b) crack opening

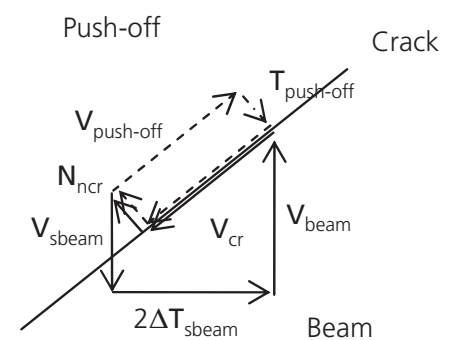

(a)

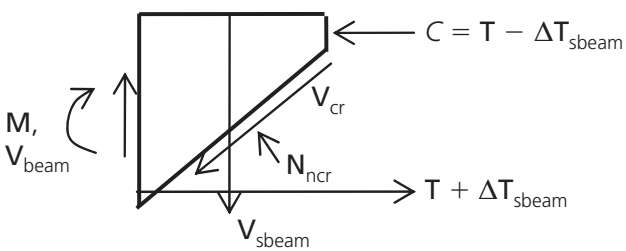

(b)

Figure 15. Equilibrium of forces at crack in beam and push-off specimen: (a) vector diagram of forces; (b) resultant forces acting on inclined shear crack in beam. $\mathbf{N}_{\text {ncr }}=$ crack normal force,

$\mathbf{T}_{\text {push-off }}=$ stirrup force in push-off specimen, $\mathbf{V}_{\text {sbeam }}=$ force in stirrups crossing inclined shear crack in beam

14. $v_{\text {eff }}=\tau_{\text {cr }}-\sigma_{\text {ncr }} \cot \theta$

The tensile force in the flexural reinforcement needs to increase by $\Delta T_{\text {sbeam }}$ to maintain axial equilibrium where $\Delta T_{\text {sbeam }}$ is given by

15. $\Delta T_{\text {sbeam }}=0 \cdot 5 b_{\mathrm{w}}\left(\tau_{\mathrm{cr}} \cot \theta+\sigma_{\mathrm{ncr}}\right) z$

where $z$ is the lever arm for shear and $b_{\mathrm{w}}$ is the width of the beam web.
Crack shear stresses were estimated in beams BL1 and BL2, in terms of the measured crack displacements, using the models of Hamadi and Regan (1980) and Gambarova and Karakoç (1983). Both these models conservatively predicted the shear stresses measured in PL2 when $s / w<0.7$ with the former being most realistic, as shown in Figures 10(a) and 12. Figures 16(a) and 16(b) show the effect of the differences in crack paths in the beams and push-off specimens on the crack shear stresses predicted by Gambarova and Karakoç's model. Figure 16(b) shows that the shear stresses are predicted to be up to around $30 \%$ less in the beam BL1 than the push-off specimen PL2. Figures 17(a) and 17(b) give details of beams BL1 and BL2 


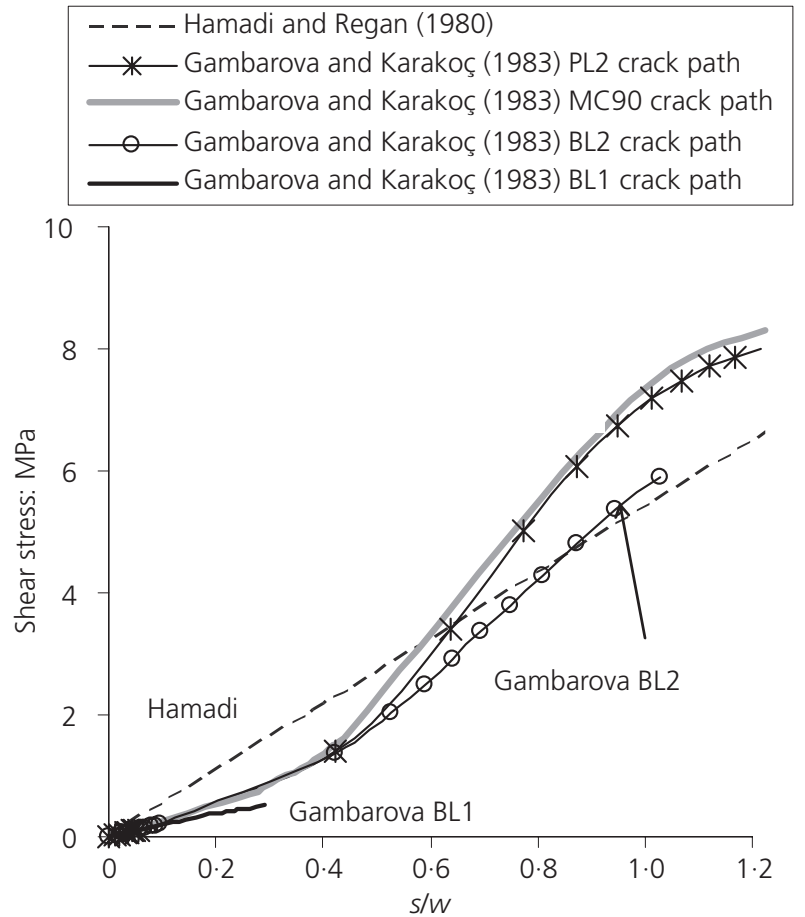

(a)

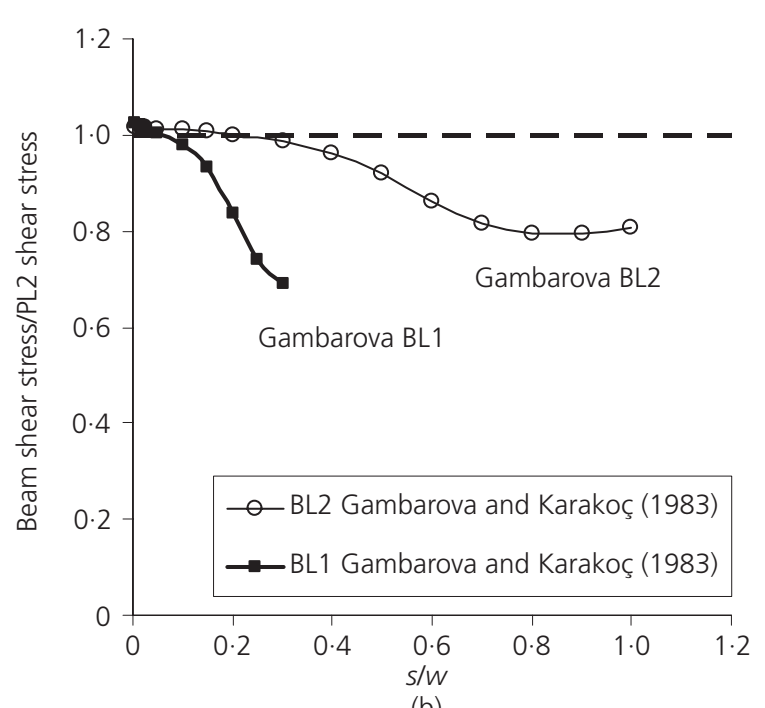

(b)

Figure 16. (a) Influence of crack path in beam and push-off tests on predicted shear stress. (b) Ratio between predicted shear stresses in beams and push-off specimens

respectively along with shear stresses calculated with the models of Hamadi and Regan (1980) and Gambarova and Karakoç (1983), which are considered to be upper and lower bounds to the actual shear stresses. The predicted shear stresses are considered reasonable for $s / w$ up to at least $0 \cdot 7$ (i.e. beyond failure of BL1 and BL2) with the model of Hamadi and Regan (1980) being most realistic. Figures 17(a) and 17(b) also show the maximum crack shear stresses allowed in the MCFT, which were calculated

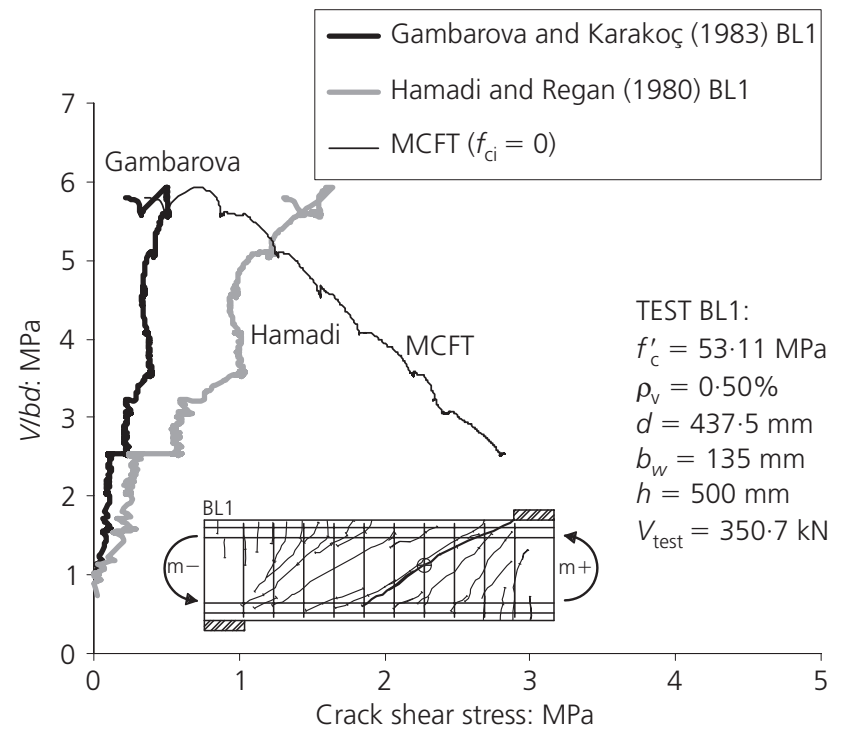

(a)

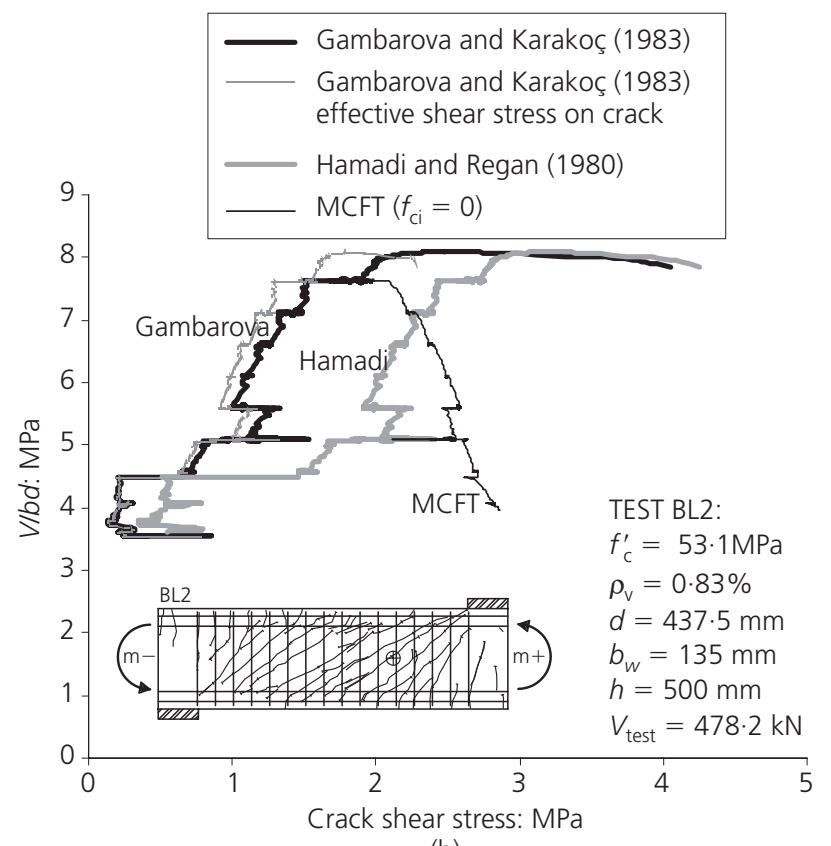

(b)

Figure 17. Estimated crack shear stresses in beams (a) BL1 and (b) BL2

with Equation 13. The crack normal stress was conservatively taken as $f_{\mathrm{ci}}=0$ in Equation 13, as assumed in the MCFT. Figure 17(b) suggests that significant shear stresses were transferred through the cracks in beam BL2 despite the aggregate fracturing at cracks. The shear transfer is believed to have been principally through the crack surfaces interlocking at the macro-level. Equation 14 was used to calculate the increase in shear resistance of beam BL2 due to interface shear. The stresses $\tau_{\text {cr }}$ and $\sigma_{\text {ncr }}$ were calculated in terms of the measured crack displacements with the model of Gambarova and Karakoç (1983). The results 
are shown in Figure 17(b), which shows that interface shear contributed significantly to the shear strength of BL2 even though the net increase in shear strength $v_{\text {eff }}$ was significantly less than $\tau_{\mathrm{cr}}$ near failure.

\section{Conclusions}

Design equations for shear rely either directly or indirectly on shear transfer through cracks, which is difficult to assess. This paper presents experimental data from push-off tests on specimens containing either gravel or limestone aggregate. These aggregates are commonly used in London for normal and highstrength concretes respectively. The cracks passed through the limestone aggregate but passed around the gravel aggregate. The crack dilatancy $(w / s)$ was almost identical in the PL and PG specimens, despite the limestone aggregate fracturing. Significant shear stresses were transferred through the cracks in the limestone specimens even though the aggregate fractured. This unexpected shear transfer capacity is believed to be due to the so-called 'macro-level roughness' observed in the tests. The experimental data were compared with the predictions of several analytical models. The stresses were typically underestimated for crack slips $<0.2 \mathrm{~mm}$ and overestimated at peak load when $s$ was $\sim 0.5 \mathrm{~mm}$. The crack dilatancy models of Hamadi and Regan (1980) and MC90 (CEB-FIP, 1990) gave the best predictions of the measured shear-slip response up to the peak shear strength. The MC90 formulae gave sensible predictions of the crack paths measured in the push-off specimens. The shear strength was found to reduce with crack width, as predicted by Equation 13 of Vecchio and Collins (1986), which includes the effects of the crack width $w$ and aggregate size. The rough crack 'shear friction' formula in Eurocode 2, which neglects the effect of $w$, gives safe predictions of the shear strengths of the tested specimens even at large crack widths.

The authors tested a series of beams with the same aggregates as used in the push-off specimens. They found that the shear strength of the beams with stirrups was unaffected by aggregate fracture. The authors estimated upper and lower bounds for the shear stresses transferred through cracks in their beams in terms of the measured crack displacements. The results are presented in Figure 17, which shows that significant shear stresses were transferred through the cracks even though the aggregate fractured.

\section{Acknowledgements}

The authors would like to acknowledge financial support from the Fundación Caja Madrid and thank the staff of the Concrete Structures Laboratory at Imperial College London.

\section{REFERENCES}

ACl (American Concrete Institute) (2008) ACI-318-08: Building code requirements for structural concrete and commentary. ACI, Farmington Hills, MI.

Bentz EC, Vecchio FJ and Collins MP (2006) Simplified modified compression field theory for calculating shear strength of reinforced concrete elements. ACI Structures Journal 103(S65): 614-624.

BSI (British Standards Institution) (2004) EN-1992-1-1: 2004, Eurocode 2: Design of concrete structures. Part 1, general rules and rules for buildings. BSI, London.

CEB-FIP (Comité Euro-International du Béton et Féderation International de la Précontrainte) (1990) MC90: Model code for concrete structures. CEB-FIP, Lausanne.

Climaco JCTS and Regan PE (2001) Evaluation of bond strength between old and new concrete in structural repairs. Magazine of Concrete Research 53(6): 377-390.

Gambarova PG and Karakoç C (1983) A new approach to the analysis of the confinement role in regularly cracking concrete elements. Proceedings of 7th International Conference on Structural Mechanics in Reactor Technology, Chicago. H: 251-261, paper H5/7.

Hamadi YD (1976) Force Transfer Across Cracks in Concrete Structures. PhD thesis, Polytechnic of Central London.

Hamadi YD and Regan PE (1980) Behaviour of normal and lightweight aggregate beams with shear cracks. The Structural Engineer 58B(4): 71-79.

Li N, Maekawa L and Okamura H (1989) Contact density model for stress transfer across cracks in concrete. Journal of the Faculty of Engineering, University of Tokyo XL(1): 9-52.

Mansur MA, Vinayagam T and Kiang-Hwee Tan (2008) Shear transfer across a crack in reinforced high-strength concrete. ASCE Journal of Materials in Civil Engineering 20(4): 294302.

Mattock JA, Johal L and Chow HC (1975) Shear transfer in reinforced concrete with moment tension acting across the shear plane. PCI Journal 20(4): 76-93.

McCarthy C (2007) Measurements of Deflections in Timber Beams by Digital Photogrammetry. MSc thesis, Imperial College London.

Millard SG and Johnson RP (1984) Shear transfer across cracks in reinforced concrete due to aggregate interlock and to dowel action. Magazine of Concrete Research 36(126): 9-21.

Millard SG and Johnson RP (1985) Shear transfer in cracked reinforced concrete. Magazine of Concrete Research 37(130): $3-15$.

Millard SG and Johnson RP (1986) Discussion on papers published in MCR 126 and 130 (contribution by Poli SD \& Gambarova PG and Karacoç C). Magazine of Concrete Research 38(134): 47-51.

Monteiro PJM and Mehta PK (1986) Interaction between carbonate rock and cement paste. Cement and Concrete Research 16(2): 127-134.

Sagaseta J (2008) The Influence of Aggregate Fracture on the Shear Strength of Reinforced Concrete Beams. PhD thesis, Imperial College London.

Sagaseta J and Vollum RL (2010) Shear design of short span beams. Magazine of Concrete Research 62(4): 267-282.

Sagaseta J and Vollum RL (2011) Influence of beam crosssection, loading arrangement and aggregate type on shear strength. Magazine of Concrete Research, in press. 
Vecchio FJ and Collins MP (1986) The modified compression-field theory for reinforced concrete elements subjected to shear. ACI Journal 83(2): 219-231.

Walraven JC and Al-Zubi N (1995) Shear capacity of lightweight concrete beams with shear reinforcement. Proceedings of Symposium on Lightweight Aggregate Concrete, Sandefjord,
Norway. Vol. 1, pp. 91-104.

Walraven JC and Reinhardt HW (1981) Theory and experiments on the mechanical behaviour of cracks in plain and reinforced concrete subjected to shear loading. Heron, Concrete Mechanics, Part A (Delft University of Technology). 26(1A): $1-680$.

\section{WHAT DO YOU THINK?}

To discuss this paper, please submit up to 500 words to the editor at www.editorialmanager.com/macr by 1 August 2011. Your contribution will be forwarded to the author(s) for a reply and, if considered appropriate by the editorial panel, will be published as a discussion in a future issue of the journal. 